\title{
On the potential vegetation feedbacks that enhance phosphorus availability - insights from a process-based model linking geological and ecological timescales
}

\author{
C. Buendía ${ }^{1,2,3}$, S. Arens ${ }^{1}$, T. Hickler ${ }^{4,5,6}$, S. I. Higgins ${ }^{6,7}$, P. Porada ${ }^{1}$, and A. Kleidon ${ }^{1}$ \\ ${ }^{1}$ Biospheric Theory and Modelling Group, Max Planck Institute for Biogeochemistry, Hans-Knöll Str. 10, 07745 Jena, \\ Germany \\ ${ }^{2}$ Bayreuth Academy of Advanced African Studies, University of Bayreuth, Hugo-Rüdel-Str. 10, 95445 Bayreuth, Germany \\ ${ }^{3}$ Ecological Modelling, University of Bayreuth, Dr.-Hans-Frisch-Str. 1-3, 95448 Bayreuth, Germany \\ ${ }^{4}$ Biodiversity and Climate Research Centre (LOEWE BiK-F), Senckenberganlage 25, 60325 Frankfurt am Main, Germany \\ ${ }^{5}$ Senckenberg Research Institute and Natural History Museum, Senckenberganlage 25, 60325 Frankfurt am Main, Germany \\ ${ }^{6}$ Institute of Physical Geography, Goethe-University, Altenhöferallee 1, 60438 Frankfurt am Main, Germany \\ ${ }^{7}$ Department of Botany, University of Otago, 479 Great King Street, 9016 Dunedin, New Zealand
}

Correspondence to: C. Buendía (coribuendia@gmail.com)

Received: 17 October 2013 - Published in Biogeosciences Discuss.: 10 December 2013

Revised: 18 May 2014 - Accepted: 6 June 2014 - Published: 9 July 2014

\begin{abstract}
In old and heavily weathered soils, the availability of $\mathrm{P}$ might be so small that the primary production of plants is limited. However, plants have evolved several mechanisms to actively take up $\mathrm{P}$ from the soil or mine it to overcome this limitation. These mechanisms involve the active uptake of $\mathrm{P}$ mediated by mycorrhiza, biotic de-occlusion through root clusters, and the biotic enhancement of weathering through root exudation. The objective of this paper is to investigate how and where these processes contribute to alleviate $\mathrm{P}$ limitation on primary productivity. To do so, we propose a process-based model accounting for the major processes of the carbon, water, and $\mathrm{P}$ cycles including chemical weathering at the global scale. Implementing $\mathrm{P}$ limitation on biomass synthesis allows the assessment of the efficiencies of biomass production across different ecosystems. We use simulation experiments to assess the relative importance of the different uptake mechanisms to alleviate $\mathrm{P}$ limitation on biomass production. We find that active $\mathrm{P}$ uptake is an essential mechanism for sustaining $\mathrm{P}$ availability on long timescales, whereas biotic de-occlusion might serve as a buffer on timescales shorter than $10000 \mathrm{yr}$. Although active $\mathrm{P}$ uptake is essential for reducing $\mathrm{P}$ losses by leaching, humid lowland soils reach P limitation after around $100000 \mathrm{yr}$ of soil evolution. Given the generalized modelling framework,
\end{abstract}

our model results compare reasonably with observed or independently estimated patterns and ranges of $\mathrm{P}$ concentrations in soils and vegetation. Furthermore, our simulations suggest that $\mathrm{P}$ limitation might be an important driver of biomass production efficiency (the fraction of the gross primary productivity used for biomass growth), and that vegetation on old soils has a smaller biomass production rate when $\mathrm{P}$ becomes limiting. With this study, we provide a theoretical basis for investigating the responses of terrestrial ecosystems to $\mathrm{P}$ availability linking geological and ecological timescales under different environmental settings.

\section{Introduction}

Phosphorus (P) is an essential nutrient for life and its availability ultimately constrains the production of biomass by primary producers, especially on old and strongly weathered soils. On ecological timescales, $\mathrm{P}$ availability depends on the efficient mineralization and recycling of organic matter (Cuevas and Medina, 1988), while over geologic timescales it depends mainly on rock weathering which is the only $\mathrm{P}$ source (Gardner, 1990; Schlesinger, 1997; Buendía et al., 2010). Because weathering rates decrease with soil age, 
primary productivity in old ecosystems may be $\mathrm{P}$ limited (Walker and Syers, 1976; Wardle et al., 2004).

Low $\mathrm{P}$ input from weathering, however, does not mean that there is no $\mathrm{P}$ in old and strongly weathered soils. It just means that most of the $\mathrm{P}$ is not available for plants, because it is in places that roots cannot access and/or occluded in secondary minerals originating from soil formation processes (Walker and Syers, 1976; Crews et al., 1995; Vitousek and Sanford, 1986). To overcome P limitation, plants have evolved strategies to make $\mathrm{P}$ available from these occluded pools and take it up more efficiently. These strategies in turn induce feedback processes between plants and soils, which ultimately lead to the enhancement of $\mathrm{P}$ availability (for a review on those strategies see Lambers et al., 2008). These feedback processes might lead to a sustained biomass production and resource acquisition (e.g. more leaves), which in turn allows for increased carbon fixation by plants and more below-ground investments, thus promoting P enhancement processes in the soil (DeLucia et al., 1997; Allen et al., 2003). While at the global scale these feedback mechanisms between plants and $\mathrm{P}$ availability in the soil determine to some extent the production and storage of biomass in ecosystems, they are also relevant for atmospheric $\mathrm{C}$ concentrations, and thus for the climate system (DeLucia et al., 1997; Zhang et al., 2011; Goll et al., 2012). If the biomass production of global vegetation is constrained by $\mathrm{P}$ availability, less carbon will be fixed to structural biomass, and therefore it will be easily respired and released to the atmosphere (Körner, 2006; Canadell et al., 2007). Hence $P$ dynamics in soils and vegetation might be crucial for understanding the terrestrial vegetation feedback on the global $\mathrm{C}$ cycle (Sardans and Peñuelas, 2012; Cernusak et al., 2013).

At the individual plant scale, $\mathrm{C}$ is assimilated during photosynthesis and stored as carbohydrates in the plant (hereafter referred to as gross primary productivity, GPP). A proportion of the assimilated $\mathrm{C}$ is respired to run the metabolic machinery of plants (i.e. autotrophic respiration); another proportion is allocated to biomass production (BP) if other essential nutrients are available; and the remaining proportion is stored as non-structural carbon (i.e. reserves such as sugars and starch) that is used to overcome unfavourable conditions in the life cycle of plants. The carbon allocated to growth and non-structural carbon is the net primary productivity (NPP).

Under P limitation, biomass production is constrained, which results in an accumulation of non-structural carbon in the plant. Some of this non-structural carbon can be transferred to the soil via root exudation (Jakobsen and Rosendahl, 1990; Körner, 2006; Bais et al., 2006) (see Fig. 1, blue box). In such cases, NPP can be substantially greater than biomass production. There are different pathways by which plants can enhance $P$ availability through root exudation. For example, (A) root exudates feed mycorrhizae that help the plant to actively take up P in dissolved forms; (B) root exudates, like citrate and oxalate (directly by the plant or mediated by soil micro-organisms) might release $\mathrm{P}$ occluded

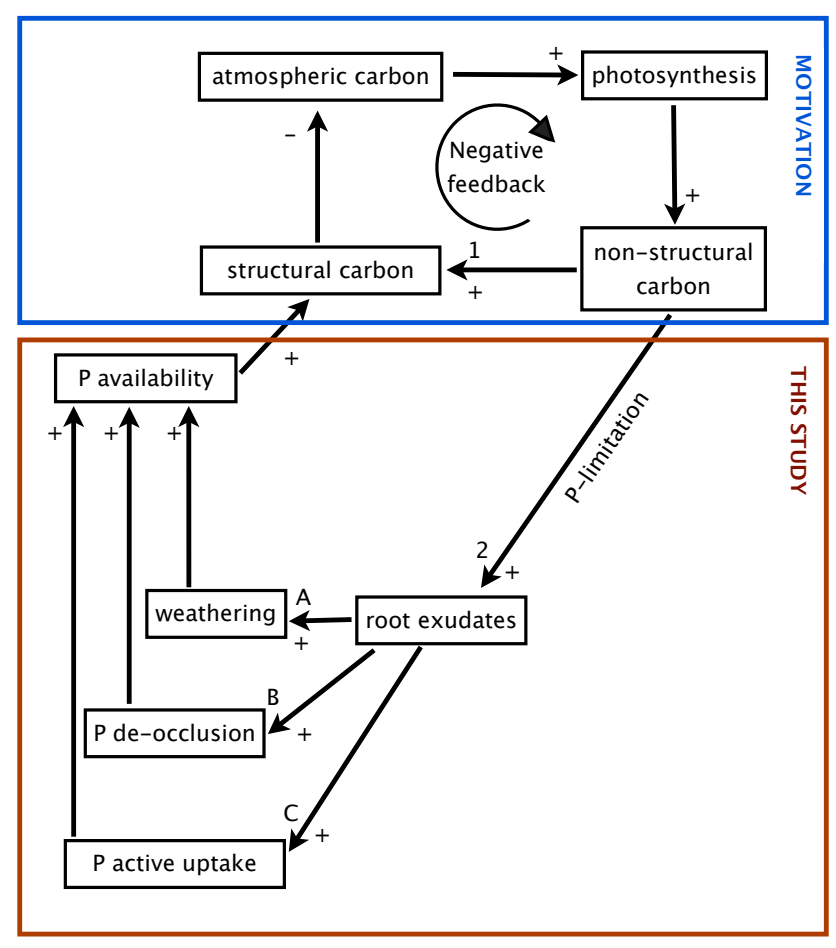

Figure 1. A conceptual diagram showing the feedback processes by which vegetation can affect $\mathrm{P}$ cycling in the pedosphere and the $\mathrm{C}$ cycle. Plants with abundant $\mathrm{P}$ supply can sequester carbon from the atmosphere and store it in biomass (path 1), which results in an overall negative feedback on atmospheric $\mathrm{CO}_{2}$ concentrations. $\mathrm{P}$-limited vegetation has a reduced capacity for producing biomass. Instead, it builds up non-structural carbon reserves that can lead to increased root exudation into the soil (path 2). Increasing root exudates increases soil respiration, potentially leading to (A) enhanced rock weathering; (B) P de-occlusion from the secondary minerals; or (C) more efficient $\mathrm{P}$ uptake by means of symbiosis with root mycorrhizae.

in secondary minerals, thus making it available for plant uptake (Banfield et al., 1999; Bais et al., 2006); (C) root exudation stimulates microbial activity and respiration in the soil. The increased microbial activity in turn increases the $\mathrm{CO}_{2}$ concentration in the soil leading to an enhancement of rock weathering (Berner, 1992; Taylor et al., 2009) and thus increased $P$ availability (Lenton, 2001), even though this process works more indirectly than the other (A and B) mechanisms.

Over $80 \%$ of terrestrial plant species have evolved P acquisition strategies (Lambers et al., 2008) and it is estimated that 10 to $20 \%$ of carbon gained by photosynthesis is used to subsidize mycorrhizal associations (Chapin et al., 2002; Allen et al., 2003). Indeed, recent observations have shown that "fertile" ecosystems can produce biomass more efficiently than infertile ones (Vicca et al., 2012). For example, nutrient-rich forests fix about $58 \%$ of their total C uptake into biomass, whereas "nutrient-poor" forests fix only about 


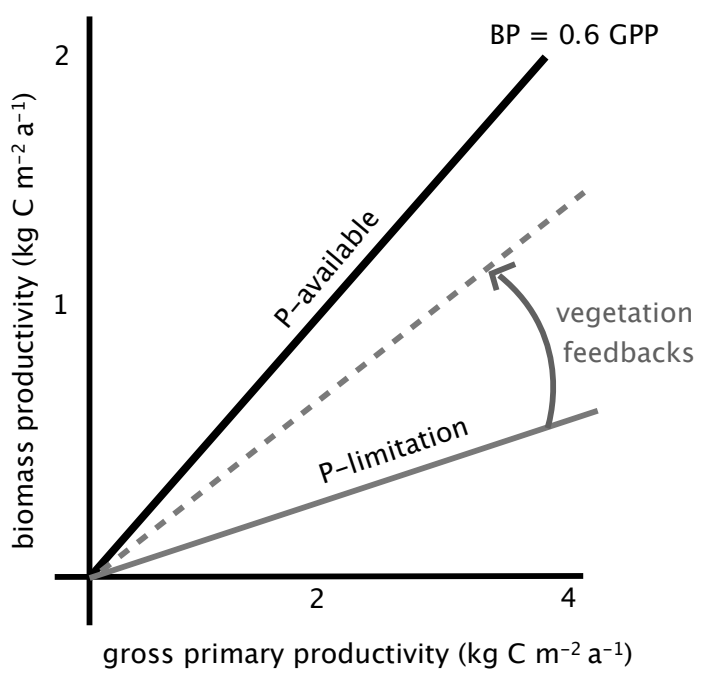

Figure 2. Theoretical relationship of $\mathrm{P}$ supply and biomass productivity (BP) efficiency. The efficiency of BP (i.e. the slope of the line) depends on the supply of P to the ecosystem and on the degree that vegetation can enhance $P$ availability. The maximum efficiency of $\mathrm{BP}$ occurs when vegetation grows under sufficient $\mathrm{P}$ (case 1, solid black line). In the other case, $\mathrm{P}$ availability limits BP (case 2, grey solid line). The carbon-energetic cost of obtaining $\mathrm{P}$ depends on vegetation-mediated processes within the soil: e.g. if root exudations results in $\mathrm{P}$ gain by vegetation, then the ecosystem can produce new biomass with this biotically acquired $P$, which then increases BP efficiency (dotted grey line).

$42 \%$ of their total C uptake into biomass (Vicca et al., 2012). Ecosystems that are not limited by nutrients (solid black line in Fig. 2) are likely to have greater relative biomass production, which would imply a strong negative feedback on atmospheric $\mathrm{CO}_{2}$ changes (i.e. case 1 in the blue frame of Fig. 1). Ecosystems that are limited by $\mathrm{P}$ availability (or other nutrients), have a lower ability to produce biomass, thus resulting in a weaker vegetation feedback on atmospheric $\mathrm{CO}_{2}$ concentrations (grey solid line in Fig. 2) unless they actively ameliorate their P limitation (grey dashed line in Fig. 2) through different processes, which also imply a $\mathrm{C}$ cost (red box in Fig. 1). Hence, $\mathrm{P}$ availability potentially constrains the biomass production efficiency of ecosystems and thereby regulates the strength of the atmospheric carbon cycle feedback.

Understanding $\mathrm{P}$ availability of the world's terrestrial ecosystems not only involves understanding $\mathrm{P}$ uptake but also involves understanding the pedogenetic processes (i.e. soil formation and evolution). Pedogenesis is a function of time, climate, composition of the parent material (lithology), topography, and involves the activity of the biota (e.g. soil organisms) (Jenny, 1958). Because climate, lithology and topography vary geographically across the globe, there is a great diversity of soil types and developmental stages. Additionally, catastrophic phenomena such as glacial retreats, soil removal and exposure of rock surfaces can reini- tiate soil formation. Vegetation further affects pedogenetic processes by mediating the fluxes of carbon and water into the soil. The interaction of the different factors involved in pedogenesis ensures that soils and their phosphorus dynamics vary. It follows that taking into account pedogenetic processes and the processes by which vegetation can enhance $\mathrm{P}$ availability is necessary to understand global biomass productivity and the response of terrestrial ecosystems to the anthropogenic enhancement of atmospheric $\mathrm{CO}_{2}$ concentrations.

This understanding has motivated the inclusion of $\mathrm{P}$ limitation in dynamic vegetation models (Wang et al., 2007, 2010; Mercado et al., 2011; Goll et al., 2012; Yang et al., 2014). Given the complexity of these models and the small time step at which they are run they rely on $\mathrm{P}$ soil data and assumptions of $\mathrm{C}: \mathrm{N}: \mathrm{P}$ ratios in vegetation and soil organic matter. This approach might work at the site scale (Runyan and D'Odorico, 2012) or in areas where P measurements exist (Mercado et al., 2011). However, at the global scale this approach is problematic given the difficultly of accurately measuring available P (DeLonge et al., 2013) and the high uncertainty of $\mathrm{P}$ maps resulting from extrapolating sitespecific data on P to the global scale (Yang et al., 2013). Therefore, we take a rather simple and different approach in which only the concentration of $\mathrm{P}$ in different lithologies is used to initialize the model. We let the model mechanistically calculate soil formation, weathering and erosion processes, at the same time as vegetation carbon, water and phosphorus dynamics.

The aim of this study is to estimate the effect of $\mathrm{P}$ availability on terrestrial biomass production and the extent to which vegetation can alleviate $P$ limitation by $P$ enhancement processes, using a process-based model that links processes working on ecological and geological timescales.

To do so, this paper is structured as follows. First, we provide an introduction to our model including a detailed description of the $\mathrm{P}$ cycle and how we implemented its different components into our $\mathrm{C}-\mathrm{P}$ biogeochemical model. In doing so, we also define simulation scenarios used to determine the importance of $\mathrm{P}$ enhancement processes on long-term NPP and BP. Second, we introduce the criteria we used to select a model scenario from the three simulation experiments and explain how the simulations are evaluated against observations. Third, the model performance with respect to the geographic variation of $\mathrm{P}$ in the soil and $\mathrm{C}$ in vegetation as well as their temporal dynamics is assessed. Finally, we discuss the limitations and general applicability of our approach as well as its implications.

\section{Methods}

To understand the spatial and temporal variations of $\mathrm{P}$ limitation on terrestrial productivity, we coupled a $\mathrm{P}$ model to a regolith model. The regolith model of Arens (2013) describes 
how vegetation, soil, water and carbon feedbacks influence soil formation. The model is based on the concentrations of elements in different lithological classes, topography and climate and calculates chemical weathering of primary minerals, erosion of secondary minerals, and the associated tectonic (isostatic) uplift. This model is coupled to a simple vegetation model that is forced by daily climate (i.e. precipitation, temperature, humidity) to calculate soil-vegetation water and carbon balances (Porada et al., 2010). Phosphorus weathering is described as a process depending on $\mathrm{P}$ concentration in the different lithological classes and calcium weathering, which is calculated in the regolith model. The abundance of secondary minerals (clays) calculated by the regolith model determines $\mathrm{P}$ occlusion and erosion. The (passive) $\mathrm{P}$ uptake by plants depends on their water uptake. The availability of inorganic phosphate in vegetation biomass constrains photosynthesis, as without it, the transformation of energy into Adenosine triphosphate (ATP) is not possible. Synthesis of vegetation biomass requires inorganic $\mathrm{P}$ to form phospholipids and genetic material; without $\mathrm{P}$ the synthesis of metabolic active tissue is not possible. The carbohydrates that are neither respired nor synthesized into biomass accumulate in the plant. A fraction of these carbohydrates can be utilized as root exudates. Root exudates are rapidly respired in the soil thus altering the soil $\mathrm{CO}_{2}$ balance as represented in Fig. 1 path $\mathrm{A}$. Biotic $\mathrm{P}$ uptake and $\mathrm{P}$ de-occlusion as represented in Fig. 1 paths $\mathrm{B}$ and $\mathrm{C}$ also depend on root exudation but have different effects in the soil as the first only uses the $\mathrm{P}$ that is in the soil in available forms, and the second uses the $\mathrm{P}$ that is bound to secondary minerals. These processes are also included in the model and can be switched on and off allowing simulation experiments that test the relative importance of the three processes on the biomass production by vegetation.

\subsection{Model formulation}

The biochemical model used here explores the short (daily) and long-term (thousand to hundred thousand years) interactions between the biogeochemical $\mathrm{C}$ and $\mathrm{P}$ cycles, given (fixed) lithological, topographical and climatological constraints. The model runs on a global scale in which the fluxes of water, carbon, phosphorus and heat between the soil and vegetation are calculated on a daily time step. The model also accounts for the pools of calcium, silicates and other primary mineral fluxes in the bedrock and their export to the soil. The diagram shown in Fig. 3 summarizes the model inputs, compartments and outputs.

The basic version of the model, which is called JESSYSIMBA, was conceived as a simple global model of terrestrial biogeochemistry accounting for the most important fluxes of carbon and water. This version is well documented and tested in Porada et al. (2010). An extension of JESSYSIMBA, including soil formation, erosion and weathering, called the regolith model was documented and tested by

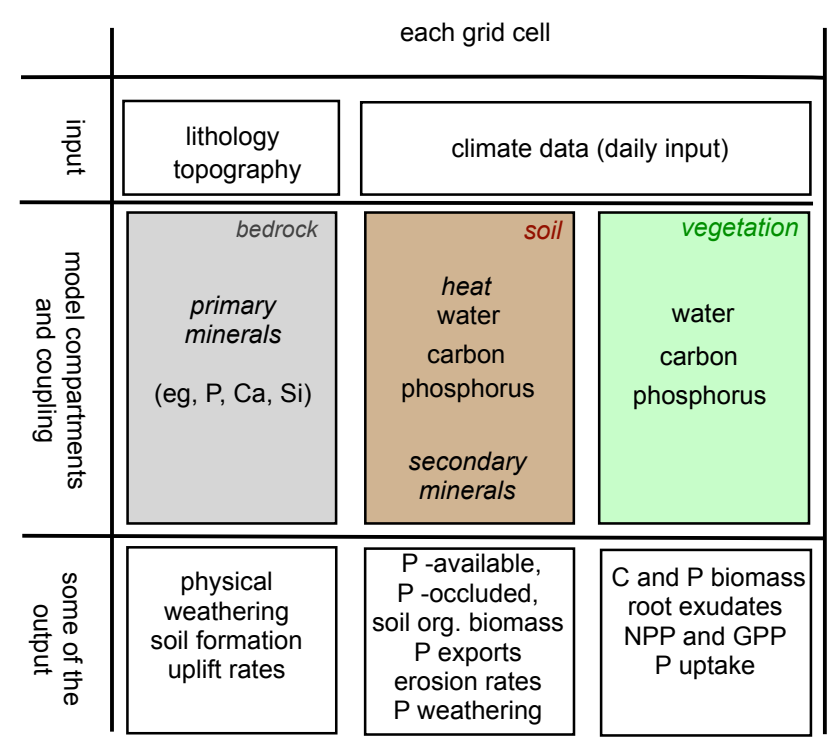

Figure 3. Diagram of the model structure (after Porada et al., 2010). The model uses daily climate data, topography and lithological classes as input. It has three main components - bedrock, soil and vegetation in which fluxes of primary minerals from the bedrock are calculated. Vegetation dynamics drive water, carbon and phosphorus dynamics. The model calculates e.g. weathering rates, gross primary productivity and biomass production. For an extensive list of the model outputs see Table A3

Arens (2013). The regolith model provides the carbon cycling module of the C-P model. This model was used here because it captures well the global patterns of $\mathrm{Ca}^{2+}$ and $\mathrm{HCO}^{-3}$ fluxes across climatic and tectonic gradients, which are derived from weathering. The $\mathrm{P}$ model described in Buendía et al. (2010) was the basis of the P dynamics module, and it captures the general dynamics of $\mathrm{P}$ in pedogenesis and soil moisture effects on $\mathrm{P}$ dynamics. To couple $\mathrm{C}$ and $\mathrm{P}$ dynamics, a number of changes in the soil and vegetation $\mathrm{C}$ dynamics were necessary: (1) the carbon pool in vegetation was split into structural carbon $\mathrm{C}_{0}^{\mathrm{v}}$, and storage carbon $\mathrm{C}_{\mathrm{c}}^{\mathrm{v}}$; (2) the storage carbon from vegetation flows to the soil generating a new flux and pool of organic carbon in the soil $\mathrm{C}_{\mathrm{c}}^{\mathrm{s}}$; (3) the inclusion of biotic de-occlusion of $\mathrm{P}$ resulted in a pool of carbon associated with secondary minerals (e.g. aluminium citrate) $\mathrm{C}_{\mathrm{y}}^{\mathrm{s}}$.

Figure 4 summarizes the $\mathrm{C}$ and $\mathrm{P}$ fluxes between bedrock, soil, vegetation and atmosphere as they were considered in this model.

A summary of the balance equations of water, carbon, calcium and phosphorus can be found in Appendix A. For the description of symbols and parameters used explicitly in the $\mathrm{P}$ cycle see Tables A3 and A4. We followed the JESSYSIMBA naming convention. State variables are conventionally named $A_{b}^{c}$, where $A$ is a chemical compound, e.g. P, or a state variable such as temperature $T, b$ is the state of matter, e.g. s for solid (see Table 1). Fluxes have names of the 


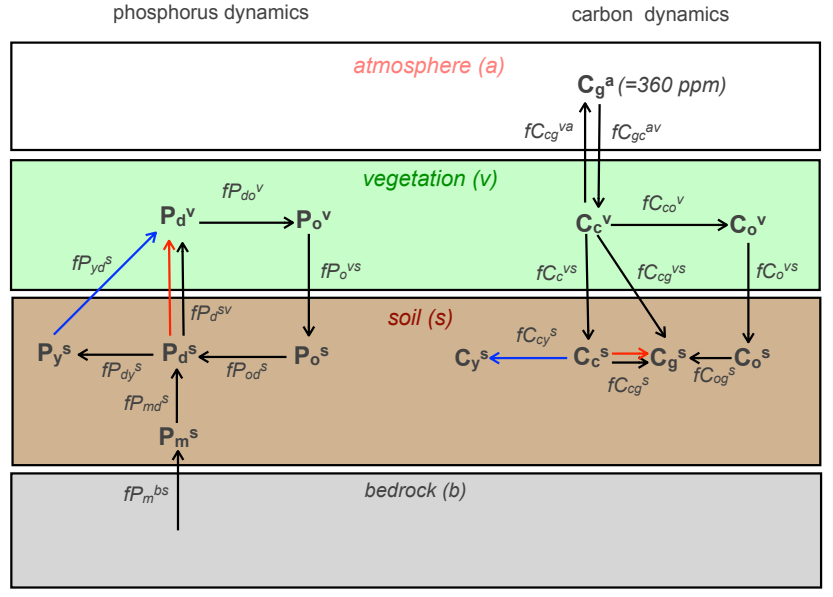

Figure 4. The C-P biogeochemical model: symbols in bold denote pools and symbols, in italic denote fluxes between pools. Black arrows show fluxes in the standard version of the model (W-P); blue arrows show $\mathrm{P}$ de-occlusion and the associated carbon flux to recalcitrant forms (BD); red arrows show $\mathrm{P}$ active uptake mediated by mycorrhizae and its associated carbon respiration (BAU). The model has a switch for turning on and off active P uptake (blue fluxes) and biotic de-occlusion of $\mathrm{P}$ (red fluxes). For definition of symbols see Table A3.

form $f A_{b t}^{s a}$, where $b$ is start and $t$ the end state (to consider phase change) and $s$ is the start and $a$ the end location. P root uptake from soil to vegetation is thus named $f \mathrm{P}_{\mathrm{d}}^{\mathrm{sv}}$.

\subsection{Bedrock related processes}

\subsubsection{Weathering}

The main input of $\mathrm{P}$ to terrestrial ecosystems is chemical weathering; therefore, an appropriate implementation of the weathering fluxes in the model is essential. To estimate weathering rates globally, tectonic uplift rates and $\mathrm{P}$ concentrations in primary minerals are needed. Arens (2013) solves this problem by assuming that uplift equals erosion. The topographic relief is constant through simulation time, which means that there must be uplift, or else topographic relief would decline. In principle, in steady state, minerals of the bedrock constantly replace eroded material, so the weight of the soil column remains constant (on a yearly basis). Only few minerals contain $\mathrm{P}$ in large amounts, in igneous rocks it is present in tiny crystals in the form of fluorapatite, while in sedimentary rocks it is found associated with authigenic carbonate fluorapatite (Filippelli, 2008). P concentration is higher in igneous rocks than in sedimentary rocks. To account for this differences the model uses the lithological map of Amiotte Suchet and Probst (1995) with apatite concentration of primary mineral estimated from Newman (1995) see Fig. 5).

Tectonic uplift of apatite from the bedrock to soil $\left(f \mathrm{P}_{\mathrm{m}}^{\mathrm{bs}}\right)$ is defined as uplift rate (uplift) multiplied by the concentration
Table 1. Abbreviations of variable names. State variables are conventionally named $\mathrm{A}_{b}^{c}$, where $\mathrm{A}$ is a chemical compound, e.g. $\mathrm{P}$, or a state variable such as temperature $T, b$ is the state of matter, e.g. s for solid (see Table 1). Fluxes have names of the form $f \mathrm{~A}_{b t}^{s a}$, where $b$ is start and $t$ the end state (to consider phase change) and $s$ is the start and $a$ the end location. P root uptake from soil to vegetation is thus named $f \mathrm{P}_{\mathrm{d}}^{\mathrm{sv}}$. Pools start with the element, fluxes start with $f$, parameters with $p$, and constants with $c$.

\begin{tabular}{llc}
\hline & & Abbreviation \\
\hline \multirow{2}{*}{ Element } & water & $\mathrm{H}_{2} \mathrm{O}$ \\
& phosphorus & $\mathrm{P}$ \\
& calcium & $\mathrm{Ca}$ \\
& carbon & $\mathrm{C}$ \\
\hline \multirow{2}{*}{ State } & solid & $\mathrm{S}$ \\
& liquid & $\mathrm{l}$ \\
& gaseous & $\mathrm{g}$ \\
& dissolved & $\mathrm{d}$ \\
& actively metabolizing biomass & $\mathrm{o}$ \\
& carbohydrates & $\mathrm{c}$ \\
& bound to primary mineral & $\mathrm{m}$ \\
& bound to secondary mineral & $\mathrm{y}$ \\
\hline \multirow{2}{*}{ Reservoir } & atmosphere & $\mathrm{a}$ \\
& vegetation & $\mathrm{v}$ \\
& soil & $\mathrm{s}$ \\
& river channel & $\mathrm{r}$ \\
& bedrock & $\mathrm{b}$ \\
\hline
\end{tabular}

of apatite $(p \mathrm{P})$, given by the lithology (see Fig. $5 \mathrm{P}$ concentrations and for global patterns):

$f \mathrm{P}_{\mathrm{m}}^{\mathrm{bs}}=p \mathrm{P}($ uplift $)$

The weathering module has been already tested and documented for calcium fluxes in Arens (2013). Since phosphorus in rock material is a trace mineral, we calculate $\mathrm{P}$ weathering as a sub-product of calcium weathering $\left(f \mathrm{Ca}_{\mathrm{pd}}\right)$ :

$f \mathrm{P}_{\mathrm{md}}^{\mathrm{s}}=f \mathrm{Ca}_{\mathrm{pd}} \frac{\mathrm{P}_{\mathrm{m}}^{\mathrm{s}}}{\mathrm{Ca}_{\mathrm{p}}}$

where $\mathrm{P}_{\mathrm{m}}^{\mathrm{s}}$ and $\mathrm{Ca}_{\mathrm{p}}$ are the concentrations of $\mathrm{P}$ and $\mathrm{Ca}$ in primary minerals in the soil (see Appendix A5 for the balance equations). Note that calcium fluxes follow the notation proposed in Arens (2013) instead of the notation proposed in Porada et al. (2010).

\subsubsection{Secondary mineral formation and $P$ occlusion}

Primary rocks react with $\mathrm{CO}_{2}$ and water, releasing its components in dissolved forms - some of these components leave the soils with the base flow (e.g. $\mathrm{Si}, \mathrm{Ca}$ ) or are taken up by vegetation (e.g. $\mathrm{P}$ and $\mathrm{Ca}$ ), while other minerals (e.g. $\mathrm{Al}, \mathrm{Fe}$ and $\mathrm{Mn}$ ) stay in the soil, forming secondary minerals. However, when soil is not well drained, Ca accumulates supersaturating the soil solution. Supersaturation stops 


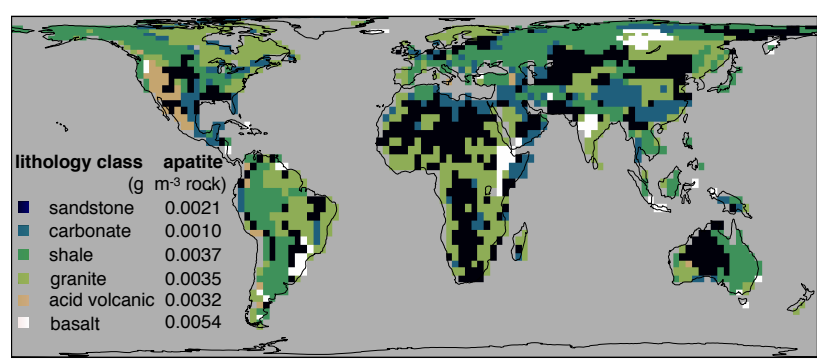

Figure 5. Map of the lithological classes and their respective apatite concentrations ( $\mathrm{g}$ apatite $\mathrm{m}^{-3}$ ). Lithological classes taken from Amiotte Suchet and Probst (1995), values for the concentration of apatite were calculated from Newman (1995).

the weathering reaction, resulting in weathering being limited by the calcium export capacity of the soils, which is referred to as the ecohydrological limitation to weathering (Arens and Kleidon, 2011). Whereas on landscapes with low topographic relief, where erosion is low and therefore tectonic uplift as prescribed in the model is low, the limitation to weathering is the supply of new fresh primary minerals.

The increase of secondary minerals with soil formation increases their capacity to co-precipitate phosphate by binding $\mathrm{P}$ to $\mathrm{Al}, \mathrm{Fe}$, and Mn (Filippelli, 2002). This process is referred to as $\mathrm{P}$ occlusion $\left(f \mathrm{P}_{\mathrm{dy}}^{\mathrm{s}}\right)$ in this model and is formulated as a function of secondary mineral density $\left(\mathrm{Clay}^{\mathrm{s}}\right)$ and $\mathrm{P}$ availability in the soil $\left(\mathrm{P}_{\mathrm{d}}^{\mathrm{s}}\right)$ :

$f \mathrm{P}_{\mathrm{dy}}^{\mathrm{s}}=p \tau \mathrm{P}_{\mathrm{yd}}^{\mathrm{s}}$ Clay $^{\mathrm{s}} \mathrm{P}_{\mathrm{d}}^{\mathrm{s}}$,

where $p \tau \mathrm{P}_{\mathrm{yd}}^{\mathrm{s}}$ is the occlusion rate of $\mathrm{P}$, bound by secondary minerals (y), in dissolved state (d) in the soil (s).

\subsection{Vegetation dynamics}

In regions with sufficient $\mathrm{P}$ availability, passive uptake of $\mathrm{P}$ is sufficient to satisfy vegetation demands of $P$. In regions with low $\mathrm{P}$ availability, vegetation relies on active $\mathrm{P}$ uptake mechanisms. Therefore, we formulate $\mathrm{P}$ uptake by vegetation $\left(f \mathrm{P}_{\mathrm{d}}^{\mathrm{sv}}\right)$ as a combination of passive and active $\mathrm{P}$ uptake. Root water uptake, $f \mathrm{H}_{2} \mathrm{O}_{1}^{\text {sv }}$ (i.e. flow from soils (s) to vegetation (v) in liquid form (1)), drives passive $\mathrm{P}$ uptake:

$f \mathrm{P}_{\mathrm{d}}^{\mathrm{sv}}=\operatorname{af} \mathrm{P}_{\mathrm{d}}^{\mathrm{sv}} f \mathrm{H}_{2} \mathrm{O}_{1}^{\mathrm{sv}} \frac{\mathrm{P}_{\mathrm{d}}^{\mathrm{s}}}{\mathrm{H}_{2} \mathrm{O}_{1}^{\mathrm{s}}}$.

In Buendía et al. (2010), mycorrhizal hyphae were found to be very important for maintaining $P$ in vegetation, particularity in old ecosystems. While accounting for carbon dynamics, it makes sense to associate a carbon cost with this symbiotic P uptake mechanism between plant and mycorrhiza. Therefore, the enhancement factor $a f \mathrm{P}_{\mathrm{d}}^{\mathrm{sv}}$ is defined as a function of root exudation of carbohydrates $f \mathrm{C}_{\mathrm{c}}^{\mathrm{sv}}$ of the following form:

af $\mathrm{P}_{\mathrm{d}}^{\mathrm{sv}}=1.0+c S U \tanh \left(p \tau \mathrm{P}_{\mathrm{d}}^{\mathrm{sv}} f \mathrm{C}_{\mathrm{c}}^{\mathrm{vs}}\right)$, which reaches an asymptotic limit of $c S U$ at high exudation rates. By setting the value of $c S U$ to 0 , the effect of active uptake can be switched off. For the simulations considering this feedback and presented here the maximum value that the enhancement factor can take is set to $10(c S U=10)$. Note that without this carbon-mediated mechanism the implementation of this value at the global scale led to unrealistic amounts of $\mathrm{P}_{\mathrm{d}}^{\mathrm{v}}$, particularly in areas with sufficient $\mathrm{P}$ supply.

\subsubsection{Gross primary productivity (GPP)}

In the original JESSY-SIMBA model, gross primary productivity (GPP, $f \mathrm{C}_{\mathrm{gc}}^{\mathrm{av}}$ ) was a simple parameterization of carbon and water fluxes, constrained by light, temperature, soil water and relative humidity (for details, see Porada et al., 2010). Here, motivated by the role that ATP plays in short-term energy storage for photosynthesis, gross primary productivity $\left(f \mathrm{C}_{\mathrm{gc}}^{\mathrm{av}}\right)$ is further constrained by $\mathrm{P}$ availability, $\mathrm{P}_{\mathrm{d}}^{\mathrm{v}}$ :

$f \mathrm{C}_{\mathrm{gc}}^{\mathrm{av}}= \begin{cases}\min \left(f \mathrm{C}_{\mathrm{gc}}^{\mathrm{av}}[\text { light }], f \mathrm{C}_{\mathrm{gc}}^{\mathrm{av}}[\text { water }]\right), & \mathrm{P}_{\mathrm{d}}^{\mathrm{v}}>0, \\ 0, & \mathrm{P}_{\mathrm{d}}^{\mathrm{v}}=0 .\end{cases}$

The carbohydrates taken up during photosynthesis are partially respired (autotrophic respiration). Those that remain are referred to as net primary productivity (NPP). Synthesis of structural biomass occurs only when other nutrients are also available; therefore, biomass productivity equals NPP only in cases when ecosystems are not limited by other nutrients.

\subsubsection{Biomass production and net primary productivity}

NPP for the purpose of this study is taken as $60 \%$ of GPP, as data suggest that a maximum of $60 \%$ of GPP can be allocated to biomass (Vicca et al., 2012). To calculate the synthesis of actively metabolizing biomass (BP), first the potential fluxes are calculated. The potential carbon flux is defined as NPP plus carbohydrate storage in vegetation $\left(\mathrm{C}_{\mathrm{c}}^{\mathrm{v}}\right)$, thus af $\mathrm{C}_{\mathrm{co}}^{\mathrm{v}}=0.6 f \mathrm{C}_{\mathrm{gc}}^{\mathrm{av}}+\mathrm{C}_{\mathrm{c}}^{\mathrm{v}}$ while the potential $\mathrm{P}$ synthesis is defined as a fraction, $\operatorname{cmax} f \mathrm{P}_{\mathrm{do}}$, of inorganic phosphate in vegetation $\mathrm{P}_{\mathrm{d}}^{\mathrm{v}}$, af $\mathrm{P}_{\mathrm{do}}^{\mathrm{v}}=\operatorname{cmax} f \mathrm{P}_{\mathrm{do}} \mathrm{P}_{\mathrm{d}}^{\mathrm{v}}$. Finally, the minimum between the potential fluxes is calculated:

$f \mathrm{C}_{\mathrm{co}}^{\mathrm{v}}=\min \left(a f \mathrm{C}_{\mathrm{co}}^{\mathrm{v}}, c \mathrm{CP}^{\mathrm{v}} a f \mathrm{P}_{\mathrm{do}}^{\mathrm{v}}\right)$ and $f \mathrm{P}_{\mathrm{do}}^{\mathrm{v}}=\frac{f \mathrm{C}_{\mathrm{co}}^{\mathrm{v}}}{c \mathrm{CP}^{\mathrm{v}}}$

The minimum between the potential fluxes $f \mathrm{C}_{\mathrm{co}}^{\mathrm{v}}$ is the actual biomass synthesis (or $\mathrm{BP}$ ). In cases where $\mathrm{C}$ or $\mathrm{P}$ limits $\mathrm{BP}$, the non-limiting nutrient is then stored. Carbon is stored in Crich structural carbohydrates $\mathrm{C}_{\mathrm{c}}^{\mathrm{v}}$ and the inorganic phosphate in vegetation $\left(\mathrm{P}_{\mathrm{d}}^{\mathrm{v}}\right)$. Given that those two pools have no size constraints this results in a flexible $\mathrm{C}$ to $\mathrm{P}$ ratio in vegetation, which indicates the degree of $\mathrm{P}$ limitation. Although, in real ecosystems, a high carbon to nutrient ratio also results from structural biomass that allows the vegetation to grow taller, this is not explicitly accounted for in the model. The description of vegetation coverage is changed to account for the new 
formulation of carbon in vegetation. That is because the leaf area index $\left(\mathrm{m}^{2}\right.$ leaf surface per soil surface) depends on the biomass that contains $\mathrm{P}$ and not on the carbohydrate storage. Total carbon in vegetation is then the sum of structural $C_{0}^{v}$ and storage $\mathrm{C}_{\mathrm{c}}^{\mathrm{v}}$ carbon.

\subsubsection{Autotrophic respiration}

In the original version of the model, the difference between GPP and NPP is denoted by autotrophic respiration $f \mathrm{C}_{\mathrm{v}}^{\mathrm{cg}}$ : half was respired into the soil $\left(f \mathrm{C}_{\mathrm{cg}}^{\mathrm{vs}}\right)$ and half into the atmosphere $\left(f \mathrm{C}_{\mathrm{cg}}^{\mathrm{va}}\right)$. Here, autotrophic respiration is divided into growth and maintenance. For each carbon unit fixed in structural biomass $\left(\mathrm{C}_{\mathrm{o}}^{\mathrm{v}}\right), 0.25$ carbon units are respired. Therefore, growth respiration $\left(p B P_{\mathrm{cg}}\right)$ is set to 0.25 (i.e. $p B P_{\mathrm{cg}}=0.25$ ) (Lavigne and Ryan, 1997). Maintenance respiration is defined with respect to actively metabolizing biomass $\left(\mathrm{C}_{\mathrm{O}}^{\mathrm{v}}\right)$, as follows:

$f \mathrm{C}_{\mathrm{cg}}^{\mathrm{v}}=p B P_{\mathrm{cg}} f \mathrm{C}_{\mathrm{co}}^{\mathrm{v}}+Q_{10} \mathrm{C}_{\mathrm{o}}^{\mathrm{v}}$.

Maintenance respiration depends on temperature and on the size of the structural carbon pool $\mathrm{C}_{\mathrm{o}}^{\mathrm{v}}$, therefore the $Q_{10}$ relation was used:

$Q_{10}=\frac{c q 10^{\frac{T_{\mathrm{s}}-c T \text { Melt }-10.0}{10.0}}}{p \tau \mathrm{C}_{\mathrm{o}}^{\mathrm{s}}}$.

The $Q_{10}$ relation depends merely on soil temperature $T_{\mathrm{s}}$. The decay rate is given by a global constant parameter $p \tau \mathrm{C}_{\mathrm{o}}^{\mathrm{S}}$ that is obtained by matching observations (IGBP-DIS, 1998).

\subsubsection{Carbon and phosphorus losses from vegetation}

The input of $\mathrm{C}$ and $\mathrm{P}$ into the soil via litterfall $\left(f \mathrm{C}_{\mathrm{o}}^{\mathrm{vs}}\right.$ and $f \mathrm{P}_{\mathrm{o}}^{\mathrm{vs}}$, respectively), root $\mathrm{C}$ exudation $\left(f \mathrm{C}_{\mathrm{c}}^{\mathrm{vs}}\right)$ and leaf leaching of $\mathrm{P}\left(f \mathrm{P}_{\mathrm{d}}^{\mathrm{vs}}\right)$ are proportional to their respective plant pools $\mathrm{C}_{\mathrm{o}}^{\mathrm{v}}, \mathrm{P}_{\mathrm{o}}^{\mathrm{v}}, \mathrm{P}_{\mathrm{d}}^{\mathrm{v}}$ and $\mathrm{C}_{\mathrm{c}}^{\mathrm{v}}$. For litter we used the formulation of Porada et al. (2010):

$f \mathrm{C}_{\mathrm{o}}^{\mathrm{vs}}=\frac{\mathrm{C}_{\mathrm{o}}^{\mathrm{v}}}{p \tau \mathrm{C}_{\mathrm{o}}^{\mathrm{v}}}$ for $\mathrm{C}$ and $f \mathrm{P}_{\mathrm{o}}^{\mathrm{vs}}=f \mathrm{C}_{\mathrm{o}}^{\mathrm{vs}} \frac{\mathrm{P}_{\mathrm{o}}^{\mathrm{v}}}{C_{\mathrm{o}}^{\mathrm{v}}}$ for $\mathrm{P}$,

where $p \tau \mathrm{C}_{\mathrm{o}}^{\mathrm{v}}$ represents the residence time of biomass in vegetation. Despite the changes in carbon dynamics of the vegetation, this parameter was not re-calibrated.

Root exudate residence time $p \tau \mathrm{C}_{\mathrm{c}}^{\mathrm{v}}$ is not known. However, in steady state root exudation equals carbohydrate and starch formation. Therefore, the parameter $p \tau \mathrm{C}_{\mathrm{c}}^{\mathrm{V}}$ was set by personal assessment to match total carbon in vegetation:

$f \mathrm{C}_{\mathrm{c}}^{\mathrm{vs}}=\frac{\mathrm{C}_{\mathrm{c}}^{\mathrm{v}}}{p \tau \mathrm{C}_{\mathrm{c}}^{\mathrm{v}}}$

The losses of inorganic phosphate in vegetation $\left(\mathrm{P}_{\mathrm{d}}^{\mathrm{v}}\right)$ are decoupled from the losses of $\mathrm{P}$ in biomass $\left(\mathrm{P}_{\mathrm{O}}^{\mathrm{V}}\right)$ - it has been observed that plants reabsorb $\mathrm{P}$ before dropping the leaves.
Probably they can reabsorb inorganic $\mathrm{P}$ used for photosynthesis, but not the organic $\mathrm{P}$ that is found in DNA or phospholipids. A minimal fractional loss was defined to avoid supersaturation of $\mathrm{P}$ of plants in regions with high $\mathrm{P}$ availability:

$f \mathrm{P}_{\mathrm{d}}^{\mathrm{vs}}=\frac{\mathrm{P}_{\mathrm{d}}^{\mathrm{v}}}{p \tau \mathrm{P}_{\mathrm{d}}^{\mathrm{v}}}$.

\subsection{Soil processes}

\subsubsection{Decomposition}

Organic matter decomposition $\left(f \mathrm{C}_{\mathrm{og}}^{\mathrm{s}}\right.$ and $\left.f \mathrm{P}_{\mathrm{od}}^{\mathrm{s}}\right)$ is a process mediated by soil fungi and microbes, whose rates of activity depend on soil moisture and temperature, substrate supply and nutrient availability (Davidson and Janssens, 2006). In JESSY-SIMBA decomposition depends merely on temperature since that better predicts the soil organic biomass patterns (Gholz et al., 2000):

$f \mathrm{C}_{\mathrm{o}} g^{\mathrm{s}}=\mathrm{C}_{\mathrm{o}}^{\mathrm{s}} Q_{10}$ and $f \mathrm{P}_{\mathrm{od}}^{\mathrm{s}}=f \mathrm{C}_{\mathrm{og}}^{\mathrm{s}} \frac{\mathrm{P}_{\mathrm{o}}^{\mathrm{s}}}{\mathrm{C}_{\mathrm{o}}^{\mathrm{s}}}$.

The model assumes that carbon root exudates are respired almost entirely by mycorrhizae and soil micro-organisms (Kunc and Macura, 1966), which is expressed by the flux $p M y \mathrm{C}_{\mathrm{cg}} f \mathrm{C}_{\mathrm{c}}^{\mathrm{vs}}$, where $p M y \mathrm{C}_{\mathrm{cg}}$ is a parameter that accounts for respiration. Only small amounts of carbon root exudates reach the mineral soil, and those follow also the $Q_{10}$ relation (Eq. 8). Heterotrophic respiration of root exudates is thus described as

$f \mathrm{C}_{\mathrm{cg}}^{\mathrm{s}}=p M y \mathrm{C}_{\mathrm{cg}} f \mathrm{C}_{\mathrm{c}}^{\mathrm{vs}}+\mathrm{C}_{\mathrm{c}}^{\mathrm{s}} Q_{10}$.

\subsubsection{Biotic de-occlusion of $P$}

In very old weathered soils, like those of western Australia, some of the plants have cluster roots instead of mycorrhiza associations (Lambers et al., 2008). Those roots produce carboxylates (e.g. oxalate and citrate), which can replace the $\mathrm{P}$ that is bound to aluminium and iron, and thus release this P (Bais et al., 2006; Lambers et al., 2008). This relation requires one sugar ( six moles $\mathrm{C}$ ) per one exchanged $\mathrm{P}\left(c C \mathrm{P}_{\mathrm{y}}^{\mathrm{s}}\right)$. Although we do not account for the process in molecular detail, organic acids are respired at a very high rate, with less than $5 \%$ reaching the mineral soil (Kunc and Macura, 1966). The remaining carbon $\mathrm{C}_{\mathrm{c}}^{\mathrm{s}}$ might be used for $\mathrm{P}$ to $\mathrm{C}$ exchange. Therefore, $\mathrm{P}$ de-occlusion is calculated as the minimum between occluded $\mathrm{P}$ (namely $\mathrm{P}_{\mathrm{y}}^{\mathrm{s}}$ ) and plant root exudates in the soil $\mathrm{C}_{\mathrm{c}}^{\mathrm{s}}$

$f \mathrm{P}_{\mathrm{yd}}^{\mathrm{sv}}=\min \frac{\mathrm{P}_{\mathrm{y}}^{\mathrm{s}}}{p d t}, c \mathrm{CP}_{\mathrm{y}}^{\mathrm{s}} \frac{\mathrm{C}_{\mathrm{c}}^{\mathrm{s}}}{p d t}$ and $f \mathrm{C}_{\mathrm{cy}}^{\mathrm{ss}}=f \mathrm{P}_{\mathrm{yd}}^{\mathrm{sv}} c \mathrm{CP}_{\mathrm{y}}^{\mathrm{s}}$.

With the introduction of this process a new pool of carbon in the soil is created, which accounts for the carbon that was exchanged with $\mathrm{P}$ in secondary minerals (e.g. aluminium citrate). We refer to this pool as the recalcitrant carbon in the soil, $\mathrm{C}_{\mathrm{y}}^{\mathrm{v}}$. 


\subsubsection{P losses}

Phosphorus is lost from the system by baseflow $f \mathrm{H}_{2} \mathrm{O}_{1}{ }^{\text {sc }}$ and erosion (driven by topography and atmosphere). Our model accounts for baseflow losses (i.e. losses of $\mathrm{P}$ from percolating water) of dissolved $\mathrm{P}$ and erosion-caused losses of occluded $P$. The reasons for excluding losses of litter and organic matter due to erosion and runoff are given in the discussion. For consistency the model does not consider atmospheric losses of $\mathrm{P}$, because atmospheric inputs of $\mathrm{P}$, via e.g. deposition of dust, are also not accounted for. This simplification will be justified in the discussion.

\section{Baseflow losses}

Losses of $\mathrm{P}_{\mathrm{d}}^{\mathrm{v}}$ are driven by baseflow (described in Eq. 9, Porada et al., 2010), which is proportional to the total concentration of $\mathrm{P}$ in the soil solution $\left(\frac{\mathrm{P}_{\mathrm{d}}^{\mathrm{sc}}}{\mathrm{H}_{2} \mathrm{O}_{1} \mathrm{~s}}\right)$,

$f \mathrm{P}_{\mathrm{d}}^{\mathrm{sc}}=f \mathrm{H}_{2} \mathrm{O}_{1}{ }^{\mathrm{sc}} \frac{\mathrm{P}_{\mathrm{d}}^{\mathrm{sc}}}{\mathrm{H}_{2} \mathrm{O}_{\mathrm{l}}^{\mathrm{s}}}$.

\section{Erosion of secondary minerals and P occluded}

The empirical formulation of physical erosion accounting for the denudation of secondary minerals driven by topographical gradients was originally proposed in Hilley and Porder (2008) (Eq. 22, Arens, 2013). Losses of occluded P are coupled to the losses of secondary minerals $\left(f\right.$ Clay $\left.^{\mathrm{sr}}\right)$ and therefore defined as

$f \mathrm{P}_{\mathrm{y}}^{\mathrm{sr}}=f$ Clay $^{\mathrm{sr}} \frac{\mathrm{P}_{\mathrm{c}}^{\mathrm{s}}}{\text { Clay }^{\mathrm{s}}}$.

Although it is not clear what happens to the recalcitrant carbon formed in the soil $\left(\mathrm{C}_{\mathrm{y}}^{\mathrm{s}}\right)$, it is assumed that baseflow drives the losses of this pool and of the organic acids pool $\mathrm{C}_{\mathrm{c}}^{\mathrm{v}}$,

$f \mathrm{C}_{\mathrm{y}}^{\mathrm{sr}}=f \mathrm{H}_{2} \mathrm{O}_{1}{ }^{\mathrm{sb}} \frac{\mathrm{C}_{\mathrm{y}}^{\mathrm{s}}}{\mathrm{H}_{2} \mathrm{O}_{1}^{\mathrm{s}}}$ and $f \mathrm{C}_{\mathrm{c}}^{\mathrm{sr}}=f \mathrm{H}_{2} \mathrm{O}_{1}{ }^{\mathrm{sb}} \frac{\mathrm{C}_{\mathrm{c}}^{\mathrm{s}}}{\mathrm{H}_{2} \mathrm{O}_{1}^{\mathrm{s}}}$.

\subsection{Simulation setup}

\subsubsection{Climate forcing}

The model was run using daily climate data from the NASA Land Surface and Hydrology archive (Sheffield et al., 2006) for the time period 1960-1989 rescaled on a global rectangular grid with a resolution of $2.810 \times 2.810$ long-lat degree Daily means of temperature, precipitation, relative humidity and long-wave and short-wave radiation were used as input to model. The glacial cover of the last glacial maximum was used to define areas where regoliths are necessarily much younger than in the rest of the world. Areas that were covered by glacial lakes were treated in the same way as areas that were covered by ice (Arens, 2013).

\subsubsection{Simulation scenarios}

Model simulations were run in low resolution $(2.810 \times 2.810$ long-lat degree) for $150000 \mathrm{yr}$. For comparison with other model estimates the model was run at a higher resolution $(1.125 \times 1.125$ long-lat degree $)$ for $70000 \mathrm{yr}$.

Figure 6 gives an overview of the processes implemented in the model and the possible feedbacks on $\mathrm{P}$ availability to vegetation. We will focus on quantifying the role of (a) biotically active $\mathrm{P}$ uptake (BAU) and (b) biotic de-occlusion of $\mathrm{P}$ (BD). A control scenario to test the enhancement of weathering through root exudation (W-P) could not be defined because $\mathrm{P}$ limitation with the proposed model structure cannot be decoupled from root exudation. Therefore, the W-P feedback cannot be quantified, but since this approach includes root exudates which change soil respiration this feedback is included in all the simulations.

1. W-P: describes the simplest dynamics of the P model. When $\mathrm{P}$ is limiting the new formation of structural biomass, carbohydrates accumulate and are released as root exudates. The exudates are quickly respired in the soil. This might enhance weathering in regions where $\mathrm{CO}_{2}$ is the limitation to weathering as described in Arens (2013). This simulation is run only for 50 thousand years, as the vegetation becomes very P limited.

2. $B D$ : biotic de-occlusion of $\mathrm{P}$ from the occluded pool. In this simulation root exudates interacted with secondary minerals to exchange $C$ with $P$ as described in Eq. (14). This also includes the possible root exudates feedback on weathering. This simulation was run for $50000 \mathrm{yr}$.

3. $B A U$ : biotic active uptake of $\mathrm{P}$ from the available pool as described in Eq. (5). In this version we assessed the role of mycorrhizae in sustaining productivity at long time scales. W-P was also included. This simulation was run for $150000 \mathrm{yr}$ at low spatial resolution and for $70000 \mathrm{yr}$ at high spatial resolution.

4. BD-BAU: includes biotic de-occlusion and biotically active uptake of P. This simulation was run for $50000 \mathrm{yr}$.

5. Control: in this simulation vegetation was provided with $\mathrm{P}$ depending on its needs in order to get the maximum biomass production rate. The model simulation reached the maximum BP to GPP rate given by the model $\left(p f \mathrm{C}_{\mathrm{co}}^{\mathrm{v}}=0.6\right)$. In this simulation root exudation was set to 0 and BP was unlimited by P. This simulation was run for one thousand years, as it was only used for controlling standing biomass and net and biomass productivity. 


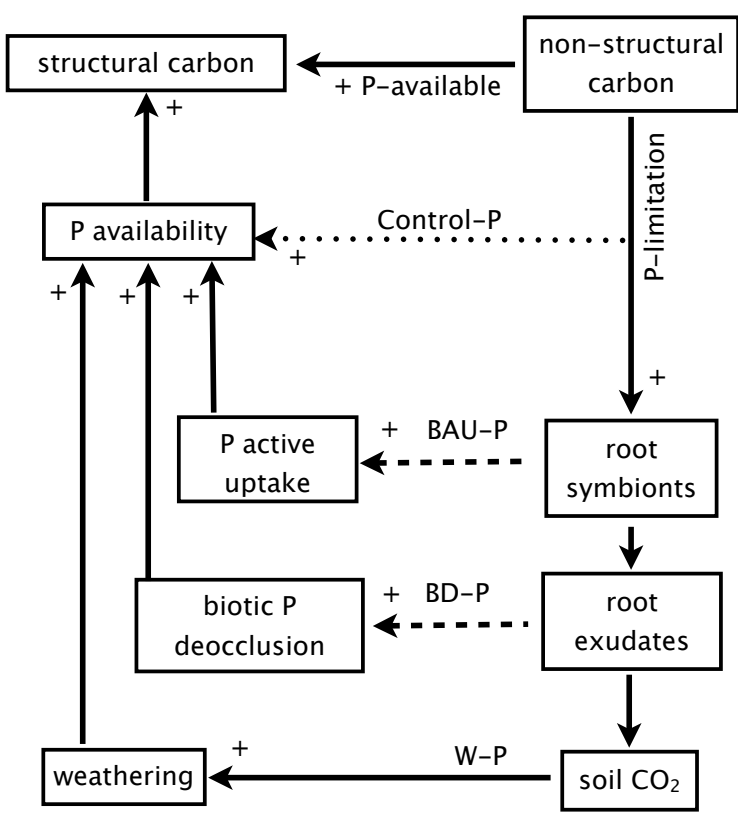

Figure 6. Diagram showing the modelled carbon feedbacks on the $P$ availability. Simulation scenarios are defined with respect to these feedbacks. Dashed line represents the effects that can be turned off and dotted line represents the unrealistic Control-P.

\subsubsection{Assessment of vegetation feedbacks on $P$ availability}

Since the carbon dynamics of the model were changed with the coupling to the $\mathrm{P}$ cycle, comparison of our results with the results presented in Porada et al. (2010) was not suitable. A scenario in which $\mathrm{P}$ dynamics were included, but the vegetation was unlimited by $\mathrm{P}$, was defined as the biomass control scenario to which all other scenarios were compared. Standing biomass was calculated as $10 \mathrm{yr}$ means at every $50000 \mathrm{yr}$ intervals. The scenario in which the $\mathrm{C}$ feedbacks on the $\mathrm{P}$ cycle could most effectively reduce $\mathrm{P}$ limitation (i.e. smallest difference in standing biomass to the control scenario) was selected for further simulations, using higher spatial resolution.

\subsubsection{Model evaluation}

After comparing the different scenarios, we choose the less P-limited and closer-to-observations scenario to run the model for $70000 \mathrm{yr}$ at a high resolution $(1.125 \times 1.125$ longlat). To evaluate our model's performance, we compared the geographical patterns of soil $\mathrm{P}$ pools to the data-driven model-estimated P soil pools of Yang et al. (2013), and to results of the model study of Goll et al. (2012).

For the evaluation of temporal dynamics, the model was run only until $150000 \mathrm{yr}$ because already at 40,000 years the regolith model reaches steady state (Arens, 2013). Low resolution $(2.810 \times 2.810$ long-lat $)$ was used to reduce the com- putational cost. Five-year means were calculated at 10000 ; 50000 ; and $150000 \mathrm{yr}$ for (a) the weathering fluxes, (b) C and $\mathrm{P}$ in vegetation biomass, (c) gross primary productivity, (d) biomass productivity, and (e) P availability in soil solution. We compared the model results with literature estimates and general insights gained from chronosequences.

\section{Results}

\subsection{Evaluation of vegetation feedbacks on $P$ availability}

The control-P scenario was defined so that $\mathrm{P}$ was not limiting photosynthesis and biomass production. In that scenario biomass pools reached their maximum value given the light and water constrains. Figure 7 shows the geographical biomass patterns without $\mathrm{P}$ limitation. The biomass reaches its maximum at about $24 \mathrm{~kg} \mathrm{C} \mathrm{m}^{-2}$ which is in accordance with satellite-derived estimates of total biomass (Saatchi et al., 2011).

To test the importance of the processes mediated by vegetation to enhance $\mathrm{P}$ availability we compare the control-P scenario with the other scenarios including gradually more processes. Figure 8 shows the differences in total vegetation biomass between the control-P scenario and the other four scenarios, (BD, BAU, BD-BAU and W-P, defined in Sect. 2.5) in ecosystems after $50000 \mathrm{yr}$ of soil evolution. In general, we find less differences between the control-P and the scenarios accounting for BAU (shown in the two right panels). The simplest scenario considering only the vegetation feedback on weathering (W-P) indicates that, after $50000 \mathrm{yr}$, vegetation is extremely $\mathrm{P}$ limited worldwide (top left panel). The scenario considering both W-P and biotic deocclusion (BD) shows a very similar limitation on standing biomass (bottom left panel). BAU shows less overall limitation to $\mathrm{P}$ compared to the scenarios not including it. The maximum absolute differences between W-P and BAU are about $10 \mathrm{~kg} \mathrm{C} \mathrm{m}^{-2}$.

Additionally, to explore on what timescale these processes respond, we looked at latitudinal averages of GPP and BP at 10000 and $50000 \mathrm{yr}$ of soil evolution (Fig. 9). After $10000 \mathrm{yr}$ of soil evolution, the GPP of all model scenarios coincide. After $50000 \mathrm{yr}$ W-P and BD scenarios slightly reduce their GPP near to the equator. Although all our model estimates for $10000 \mathrm{yr}$ have higher GPP than estimates by Beer et al. (2010), which were based on a global set of eddy covariance data (in the upper panels Fig. 8 referred as data), at $50000 \mathrm{yr}$ they coincide. Biomass production is in all scenarios lower then the control-P scenario, indicating widespread $\mathrm{P}$ limitation. The highest difference of biomass production is between the control and the W-P scenario. Only a small difference in biomass production is observed in the tropics between the BD and W-P scenarios, suggesting that $\mathrm{BD}$ as it is included in the model does not really help vegetation to relieve $\mathrm{P}$ limitation. The scenarios that have the 


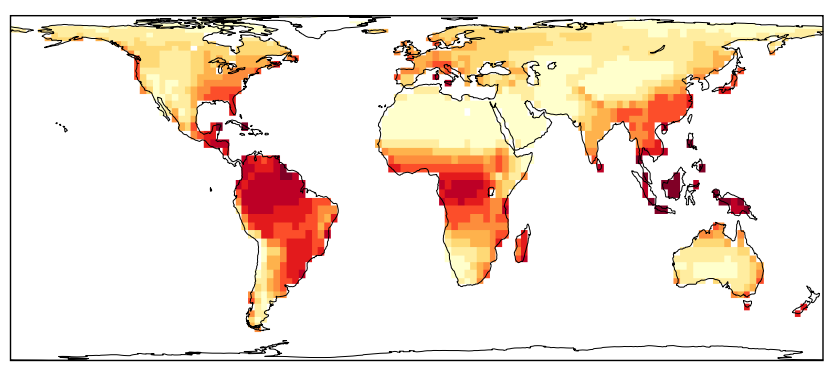

standing biomass $\left(\mathrm{kg} \mathrm{C} \mathrm{m}^{-2}\right)$

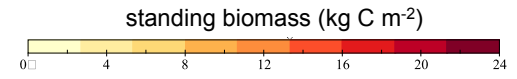

Figure 7. Carbon in terrestrial vegetation biomass of the control run. In this scenario the vegetation growth is constrained only by water, light, and temperature so that vegetation biomass reaches its maximum everywhere around the globe, while not accounting for $\mathrm{P}$ limitation. In this simulation biomass reaches $24 \mathrm{~kg} \mathrm{C} \mathrm{m}^{-2}$ in some tropical areas.

smallest differences to the control scenario are those considering BAU. After $10000 \mathrm{yr}$ BAU and BAU-BD overlap, and after $50000 \mathrm{yr}$ BAU and BAU-BD decrease with the rest to $10000 \mathrm{yr}$ although BAU-BD is slightly less. The model inter-comparison for NPP from Cramer et al. (1999), which usually is interpreted as BP, is included as a reference. The scenarios including BAU best fit this line.

Overall, mycorrhizae-mediated $\mathrm{P}$ uptake is identified as a very important mechanism in terms of maintaining ecosystem biomass during longer timescales (over $50000 \mathrm{yr}$ ). That is represented by the differences between right and left panels in Fig. 8. This process is important, not only in the tropics, but also in temperate regions. Therefore, BAU was included in further simulations. In contrast, including the $\mathrm{P}$ cycle without this carbon feedback leads to a scenario with very high limitation to biomass production. Biotic de-occlusion was inefficient due to the lack of replenishment of the $P$ that was occluded. Simulations including this feedback led to unrealistic scenarios in which, particularly in the tropics, unrealistically low amounts of the P occluded were found at the end of the simulation.

Our previous results regarding vegetation $\mathrm{C}$ dynamics highlighted the importance of mycorrhizal-mediated $\mathrm{P}$ uptake and the inefficiency of biotic de-occlusion to supply $\mathrm{P}$ to old ecosystems. Regarding standing biomass patterns, the simulation including both BD and BAU imposed the smallest constraint on standing biomass. However, the difference to the scenario including just BAU was very small. The scenarios that included the BD feedback gave unrealistic $\mathrm{P}$ occluded ranges and global patterns. Therefore, the BAU scenario was run for $70000 \mathrm{yr}$ at a higher resolution to compare spatial and temporal patterns of model results with observations.

\subsection{Evaluation of modelled soil and vegetation $P$ spatial patterns and temporal dynamics}

Figure 10 shows the $\mathrm{P}$ status of soils and vegetation after $70000 \mathrm{yr}$ of simulation. Because glaciation and volcanism restart the soil forming process and are not included in our model, our map cannot accurately reproduce present conditions across the globe. However, it presents general features of how climate, topography and lithology might influence soil $\mathrm{P}$ status and vegetation productivity. Places that were glaciated during the last glacial maximum (about $21000 \mathrm{yr}$ ago) are omitted here. Because $\mathrm{P}$ in primary minerals in the bedrock was also considered, the total amount of apatite is not presented here. The occluded $\mathrm{P}$ pool is the largest $\mathrm{P}$ pool in soils. Our numbers are of the order of magnitude estimated by Yang et al. (2013) and the patterns look similar (see for comparison Appendix B, Fig. B2). The second largest pool in the soil is $\mathrm{P}$ in litter and soil organic biomass (top-right panel). Our model estimates are five times smaller than the ones given by Yang et al. (2013) (see for comparison Appendix B, Fig. B1). However, our upper range is higher than that reported for agricultural soils, $25 \mathrm{~g} \mathrm{P} \mathrm{m}^{-2}$ (Brady and Weil, 2008), and in general agreement with ranges and patterns from Goll et al. (2012). The modelled dynamics with respect to $P$ in vegetation are within the observed ranges (Brady and Weil, 2008) and also in agreement with modelled estimates by Goll et al. (2012) (see Fig. 2). Figure 11 shows the performance of vegetation including $\mathrm{P}$ dynamics. The total biomass patterns are in agreement with estimates by Saatchi et al. (2011). Although there are no big differences in the patterns of GPP and BP, the map of biomass productivity efficiency, here, is the result of $\mathrm{P}$ limitation.

Overall, we found reasonable agreement between our modelled P global patterns and independent data- and modelbased estimates, in particular considering the substantial uncertainty associated with the data sets used here for comparison. Figure 12 shows how weathering, carbon to phosphorus ratio in vegetation and biomass productivity efficiency change in time. Putting those plots together enables us to see how patterns are correlated. The $\mathrm{P}$ weathering rates, calculated from our model, are in the range of observed values (50 to $1000 \mathrm{~g} \mathrm{Pha}^{-1} \mathrm{a}^{-1}$ ) (Newman, 1995), after 10000,50000 and $150000 \mathrm{yr}$ of soil formation (see Fig. 12 central panels). Generally, the overall weathering rates decreased in time, except for mountainous regions where weathering stayed relatively constant over time. The $\mathrm{C}$ to $\mathrm{P}$ ratio is correlated with the lithological classes (see Fig. 5 for comparison) and increased over time, as the soil aged. For example, at $10000 \mathrm{yr}$ the western part of the Amazon basin had lower weathering rates compared to those from the eastern part, but over time (i.e. after $150000 \mathrm{yr}$ ) the weathering rate in the west decreased to a lesser extent than in the east, which resulted in eastern Amazon being more $\mathrm{P}$ limited (higher $\mathrm{C}: \mathrm{P}$ ratio) compared to the west. Given that the soils of the Amazon basin are millions of years old, the simulation run for 

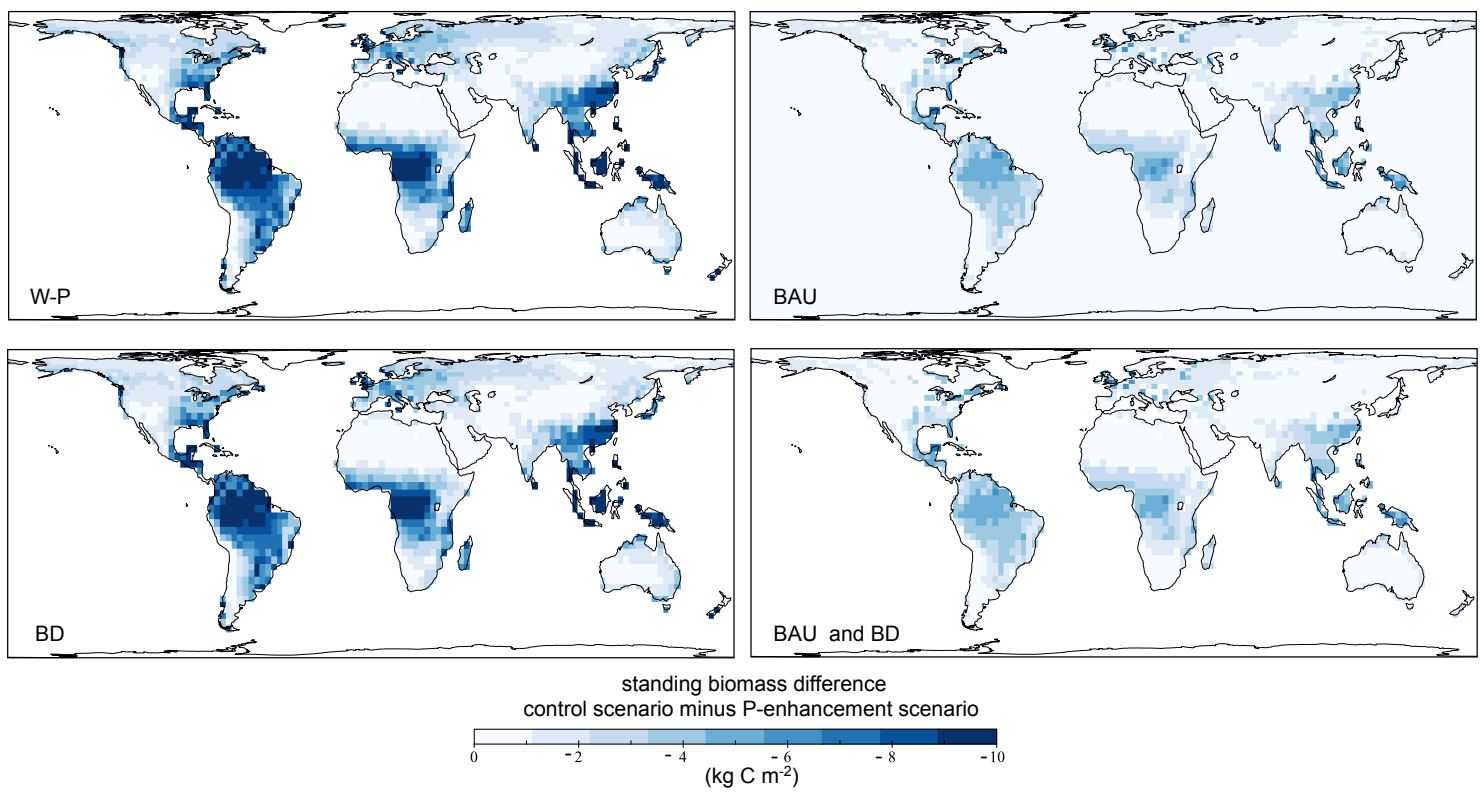

Figure 8. Difference in the standing biomass of the control with the different feedback scenarios for the world after $50000 \mathrm{yr}$ of soil evolution. Biomass differences between the control simulation (see Fig. 7) and W-P (top left), BD (bottom left), BAU (top-right), BAU-BD (bottom right). W-P shows the greatest differences with the control scenario: more than $50 \%$ biomass reduction worldwide - the differences are high in temperate coastal areas (e.g. Chile, Guyana and South Africa). BD (bottom left) shows a very similar pattern to the W-P scenario, with only small differences in temperate regions. Biotic active uptake (BAU) (top-right panel) shows much smaller differences to the control, with the absolute greatest differences located in the tropics. BAU-BD (bottom right) shows a pattern almost identical to the BAU scenario, with only very little differences.

$150000 \mathrm{yr}$ serves as the best data comparison for this area. Differences in the allocation of carbon and plant characteristics between western and eastern Amazon basin have been observed (Quesada et al., 2012; Saatchi et al., 2011). Overall, we see how the ecosystems shift towards P limitation over time. After $10000 \mathrm{yr}$ of soil formation, most of the ecosystems have enough $\mathrm{P}$ for biomass synthesis and therefore have high BP to GPP ratio (refer to left panels). However, over time (after $100000 \mathrm{yr}$ ), more ecosystems shift towards P limitation, reducing the overall biomass productivity efficiency.

\subsection{Phosphorus constraints on productivity}

In the introduction we explained how $\mathrm{P}$ availability in the soil constrains biomass production and that vegetation feedbacks on $\mathrm{P}$ availability can influence these dynamics (see Fig. 2). In the model we included the processes that make P available and also three vegetation feedbacks that could result in enhancing $P$ availability for vegetation. Figure 13 shows how biomass productivity efficiency changes over time. We have plotted here GPP vs. BP at the three different timescales of 10000,50000 and $150000 \mathrm{yr}$ to show how ecosystems get more constrained with time. Data for forest ecosystems from the study of Vicca et al. (2012) show a similar pattern, although biomass production efficiency of the forest ecosystems is in general higher than in our model. Nevertheless, our model illustrates how Biomas production efficiency (BPE) decreases in time and how GPP is decoupled from BP (see Fig. 12, left panel).

Our results on BPE suggest that $\mathrm{P}$ availability limits BP in old lowland soils and by doing so modulates the carbon cycle, although other limiting nutrients (e.g. N) surely also influence BPE in other areas. Figures 12 and 13 show how BPE changes during soil evolution. As soils evolve, most ecosystems tend to be P limited and decrease their biomass synthesis, which agrees with observations (Wardle et al., 2004) and with modelling results (Menge et al., 2012).

\section{Discussion}

The model we present here is very simple and it cannot be applied to understand processes at the plant level. Instead, the model can be seen as proof of concept of how one can account for the interactions between carbon and P limitations at the soil-vegetation level, on ecological as well as geological timescales. This work, therefore, represents a first step towards understanding how the $\mathrm{P}$ cycle constrains vegetation and how vegetation feedbacks affect $P$ dynamics.

With this simple model we show that biomass productivity, most probably, depends to some extent on the feedback processes mediated by vegetation and, more importantly, on the long-term $\mathrm{P}$ cycle. Hence, it might be essential to consider long-term processes of the $\mathrm{P}$ cycle and element synergies to 


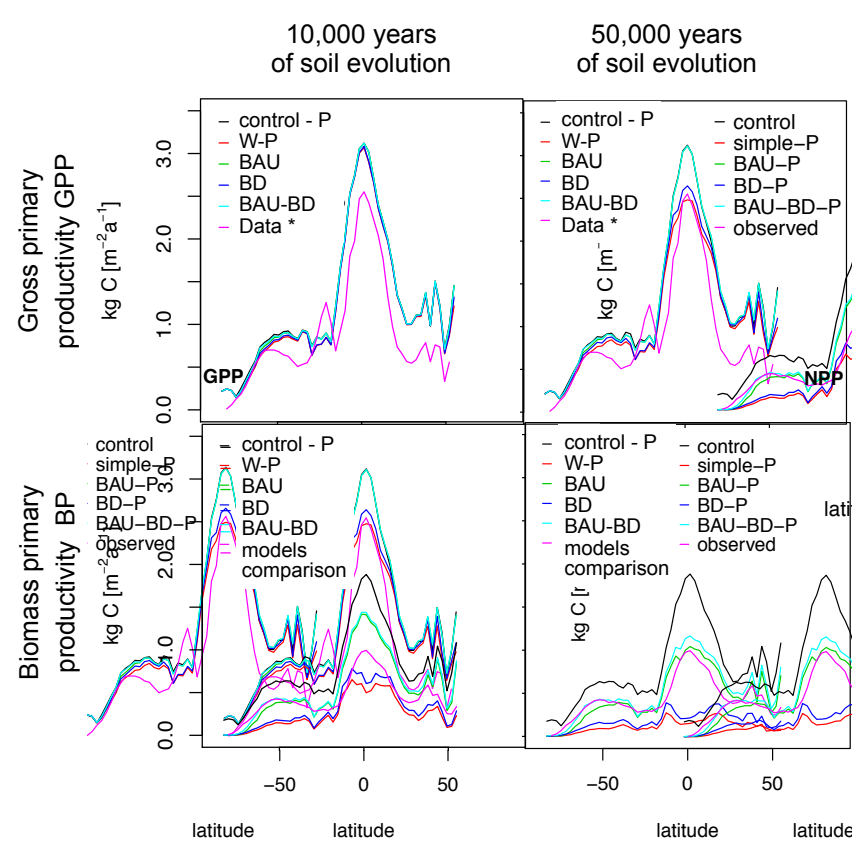

Figure 9. GPP (top panels) and BP (bottom panels) zonal averages after 10000 (left panels) and 50000 (right panels) years of soil formation. Different scenarios considered are compared with databased estimated GPP (Beer et al., 2010) and model-based estimated NPP (Cramer et al., 1999).

constrain the magnitude of the terrestrial vegetation's feedback on $\mathrm{CO}_{2}$ concentrations in a process-based modelling framework. Our model shows reasonable patterns of P stocks in soils and vegetation.

Evaluating the $\mathrm{P}$ model at the global scale is challenging given the scarcity and uncertainty of observed data. Qualitatively, the patterns of the occluded P pool look similar to the statistically modelled data from Yang et al. (2013). However, with respect to the more important pools like organic $\mathrm{P}$ in the soil, our model predicts much lower concentrations for the whole soil profile than the concentrations derived by Yang et al. (2013) for the top $50 \mathrm{~cm}$ of soil. The upper range of soil organic $\mathrm{P}$ in Yang et al. (up to $587 \mathrm{~g} \mathrm{P} \mathrm{m}^{-2}$ ) is five times larger than the upper ranges obtained by our model. We wonder about the processes that could generate the high values and high spatial variability of organic $\mathrm{P}$ forms in the Sahara region derived by Yang et al. (2013) (see Fig. B1, Appendix B). Given the current lack of vegetation cover, perhaps the organic $\mathrm{P}$ has been there for a long time, originating from lichen productivity (Porada et al., 2013), or is the remaining $P$ from periods when the Sahel region was wetter and therefore vegetated (Scheffer et al., 2001). Perhaps running the model with climates of the past will lead to a more accurate representation of the P patterns in such regions. Nevertheless, compared to the study of Goll et al. (2012) and literature ranges (Brady and Weil, 2008), our estimates are of the same order of magnitude. Therefore, given the simplicity of the model it represents $\mathrm{P}$ distribution relatively well.

The temporal dynamics of our model are consistent with data and understanding gained from chronosequences (Walker and Syers, 1976; Crews et al., 1995; Wardle et al., 2004). In regions with a low topographical gradient, $P$ becomes depleted during pedogenesis regardless of the inclusion of tectonic uplift in the model. This is accompanied by vegetation dynamics reaching a maximum productivity at intermediate $\mathrm{P}$ depletion stages and then declining, as Wardle et al. (2004) observed in chronosequences. However, our results suggest that, on long timescales, ecosystems still gain $P$ from weathering inputs. This contrasts with the general assumption that old P-depleted ecosystems merely depend on exogenous P sources (Jordan, 1982; Walker and Syers, 1976; Crews et al., 1995; Wardle et al., 2004).

This insight - that steady-state weathering is limited by the tectonic uplift - provided by our model simulations is in agreement with the result obtained by our simple $\mathrm{P}$ model (Buendía et al., 2010) that does not account for the effects of soil $\mathrm{CO}_{2}$ and soil depth. Because tectonic uplift is defined by the potential physical transport of secondary minerals and hence by topographical gradients, weathering is only limited by ecohydrological factors in mountain areas. That is, the maximum possible chemical weathering rate is determined by the ecohydrological conditions: regolith drainage, $\mathrm{CO}_{2}$, and temperature (Arens, 2013).

Our results show that ecosystems with high tectonic uplift rates (mountain regions) have a high BPE. Because ecosystems with a high topographical gradient have significant soil litter and organic biomass losses and our model does not include the processes of lateral losses of organic biomass, we think that our estimates BPE for mountain regions might be over-estimated.

\subsection{Model limitations and outlook}

The model accounts for erosion of secondary minerals, but it does not account for the erosion of primary minerals. Not accounting for this process is problematic in mountain ranges influenced by tectonic processes, like the Andes or the Himalayas, as large amounts of primary minerals are eroded, transported by rivers and deposited in flooded regions (Wittmann et al., 2006; Junk et al., 2011).

Lithology determines the concentration of $\mathrm{P}$ in the primary minerals and also how fast material weathers, which is a result of the calcium reactions considered in the regolith model of Arens (2013). Therefore, including lithology in the model was necessary to simulate the observed differences in weathering rates and steady-state development in (for example) the western and eastern Amazon. However, for some lithological classes, variations in the $\mathrm{P}$ concentration have been reported (Newman, 1995), and P concentrations also change through time. We have ignored these variations because such 

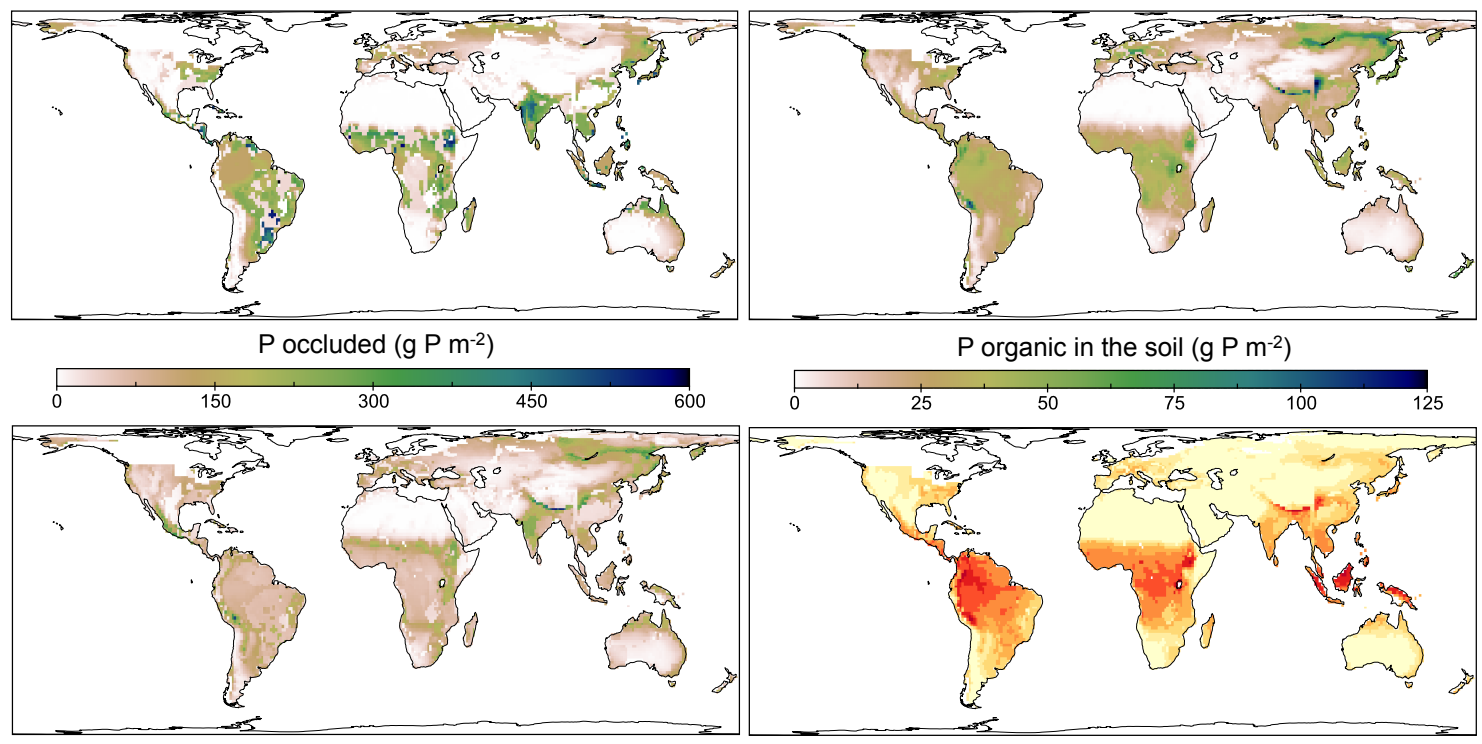

$\mathrm{P}$ in soil solution $\left(\mathrm{g} \mathrm{P} \mathrm{m}^{-2}\right)$
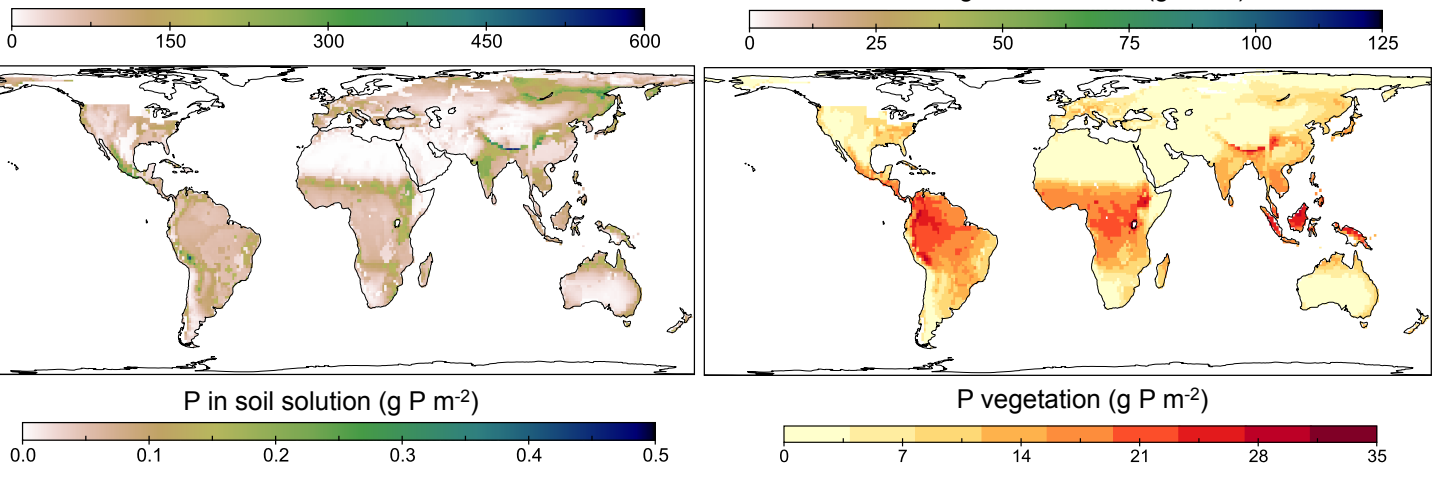

Figure 10. $\mathrm{P}$ pools in the soil considering active $\mathrm{P}$ vegetation uptake after 70000 simulated years of pedogenesis.
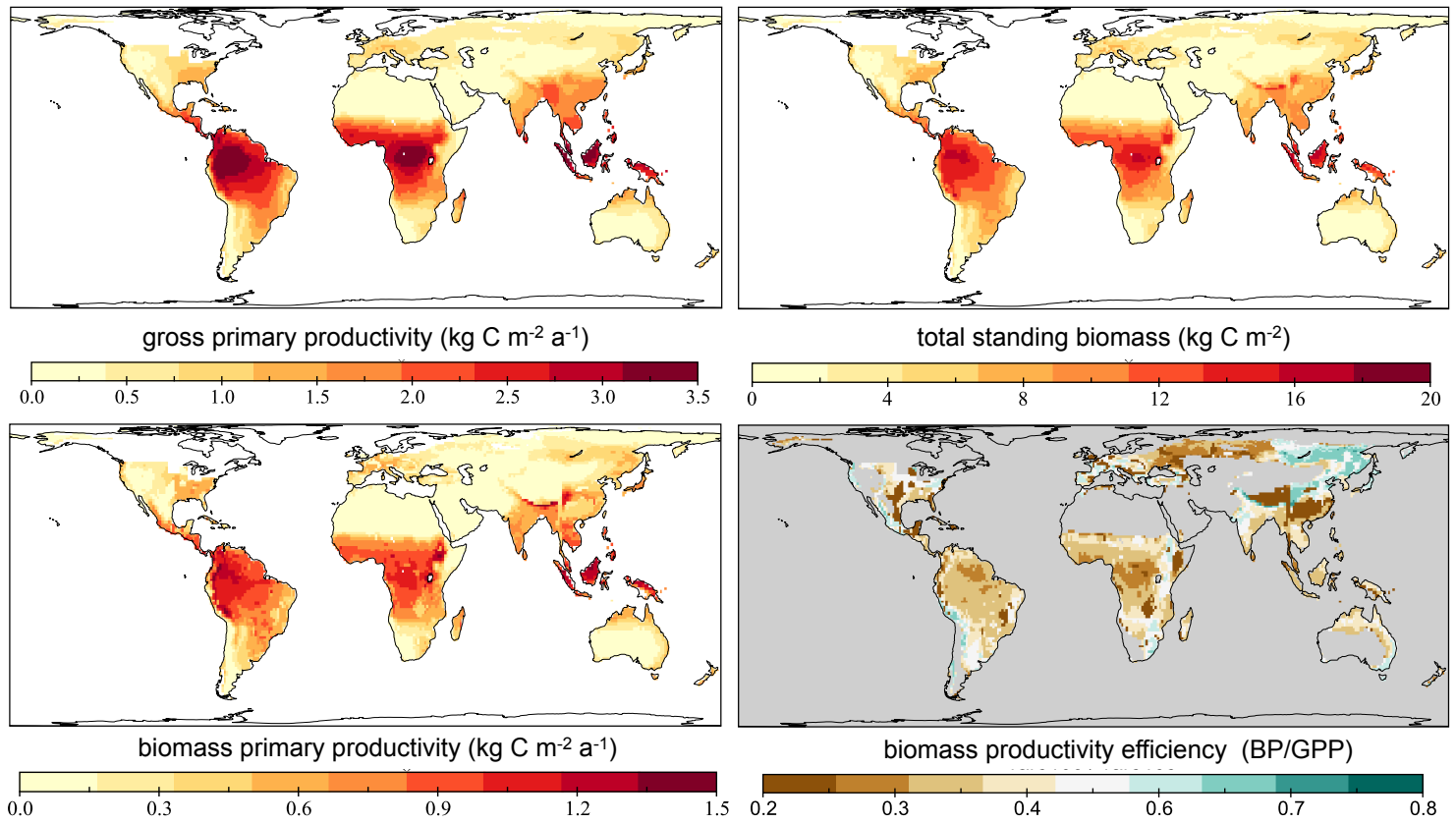

Figure 11. Carbon fluxes and pools in vegetation considering active $\mathrm{P}$ vegetation uptake after $70000 \mathrm{yr}$ of soil evolution.

information is not available for all lithological classes used in our global analysis.

Atmospheric deposition of $\mathrm{P}$, despite being considered as an important input to regions with low weathering, was not included in our model. Model-generated data on atmospheric dust deposition are available on request from Mahowald et al. (2005). However, the uncertainties associated with the data are quite high (Mahowald, personal communication). Addi- tionally, in regions like the Amazon basin the atmospheric deposition mostly originates from local redistribution of biotic particles, such as pollen and leaf fragments (Mahowald et al., 2005; Pauliquevis et al., 2012). At the global scale the atmosphere redistributes $\mathrm{P}$ from one region to the other, and therefore if this process were to be included, both $\mathrm{P}$ deposition and removal from all areas considered would have to be modelled. Therefore, we decided that we could omit this 

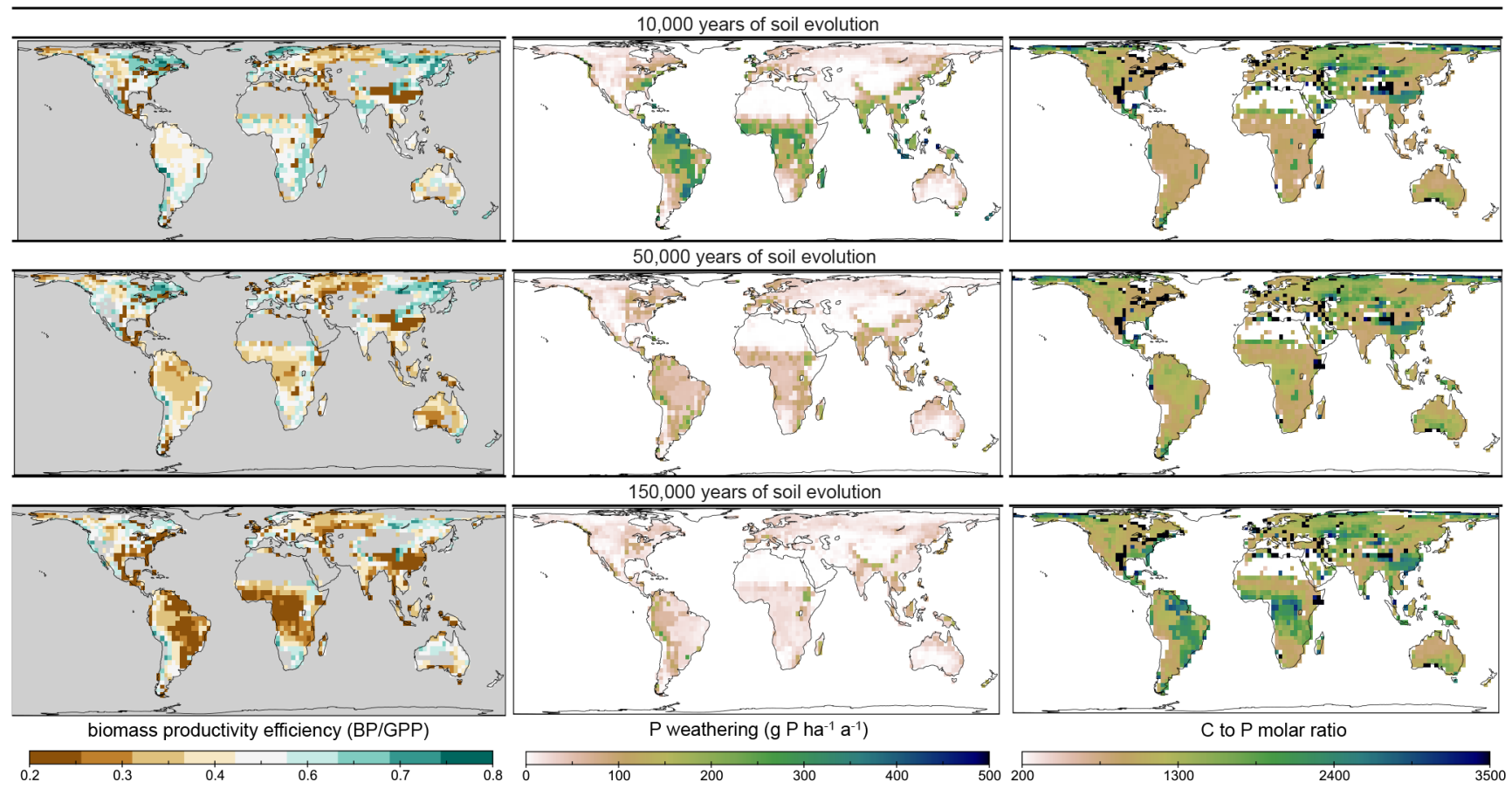

Figure 12. Biomass production efficiency (BPE), $\mathrm{P}$ weathering rates, and $\mathrm{C}$ to $\mathrm{P}$ molar ratio in vegetation changes during pedogenesis. Top plots represent the dynamics in recent soils (after about $10000 \mathrm{yr}$ of soil evolution). The intermediate plots represent intermediate soil ages of about $50000 \mathrm{yr}$ and the bottom plots represent old soils after about $150000 \mathrm{yr}$ of soil evolution. Biomass production is more efficient in temperate regions in both young and old soils. In tropical regions, BPE decreased in time, reaching a status of very low efficiency, particularly in central Africa and Western South America. P weathering rates (central panels) decrease everywhere with time. In the oldest soils, weathering is high in places at high elevations. Locations with shale lithology also produced relatively high weathering rates, compared to those with sandstone. The $\mathrm{C}$ to $\mathrm{P}$ molar ratio in vegetation increased in time. In tropical regions, the ratio was correlated with weathering rates.

process. Once the soil processes contributing to the $\mathrm{P}$ dynamics are better understood, one could try to include these processes, related to wind erosion and dust deposition.

Terrestrial ecosystems have regular losses of litter and soil organic biomass due to run-off, animals and erosion. Those losses cause losses of $\mathrm{Ca}, \mathrm{C}$ and P. For simplicity, our model does not account for these processes, since parameterizing these processes might be elusive beyond local scales. However, losses of $\mathrm{Ca}, \mathrm{C}$ and $\mathrm{P}$ due to erosion would have two contradictory consequences:

1. soil respiration will potentially decrease since the organic matter will no longer be respired in the soil, but rather in the rivers, lakes and oceans;

2. including Ca losses may increase weathering in the regions where weathering is currently constrained by high concentration of $\mathrm{Ca}$ in the soil solution.

It would be interesting in future studies to include $\mathrm{Ca}$ dynamics in vegetation, to test whether that can indeed drive the lowland ecosystems to a steady state with higher weathering rates.

The main effect of glacial interglacial cycles is that soils in temperate regions were removed during glacial times, and af- ter glacial retreat the soil formation process restarts. We run the model for $150000 \mathrm{yr}$ to let the soils reach their steady state as we mainly wanted to understand how ecosystems remain productive over time, particularly on old weathered soils like those of the Amazon. Results for $10000 \mathrm{yr}$ and $50000 \mathrm{yr}$ are presented to illustrate the transient dynamics and to represent soils that experienced glaciations. Temperature and humidity drive terrestrial primary productivity and soil organic matter decomposition. In contrast to tropical regions where primary productivity, litter production and mineralization is high, productivity and litter production rates in arid regions are lower, which may lead soil organic matter (or at least P) to accumulate. Therefore, if climate shifts from relatively dry to wet as happened in the Amazon during the last $21000 \mathrm{yr}$, the accumulated soil organic matter is decomposed and used for primary production leading to a new steady state. In contrast, in regions where climate shifted from wetter to dryer conditions, like in the Sahel region, some of the organic and occluded $\mathrm{P}$ that was produced during wet periods is preserved, for example as fossilized animal bones or in palaeo-lakes (e.g. the Bodélé Depression in Chad; Bristow et al. 2010). Remains of $P$ from palaeo-environments are visible in contemporary soil data and they may be regarded 
10,000 years of soil evolution

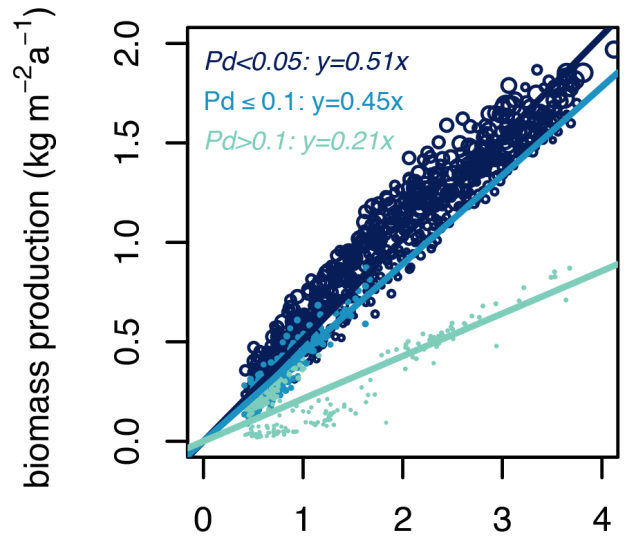

gross primary productivity $\left(\mathrm{kg} \mathrm{m}^{-2} \mathrm{a}^{-1}\right)$

150,000 years of soil evolution

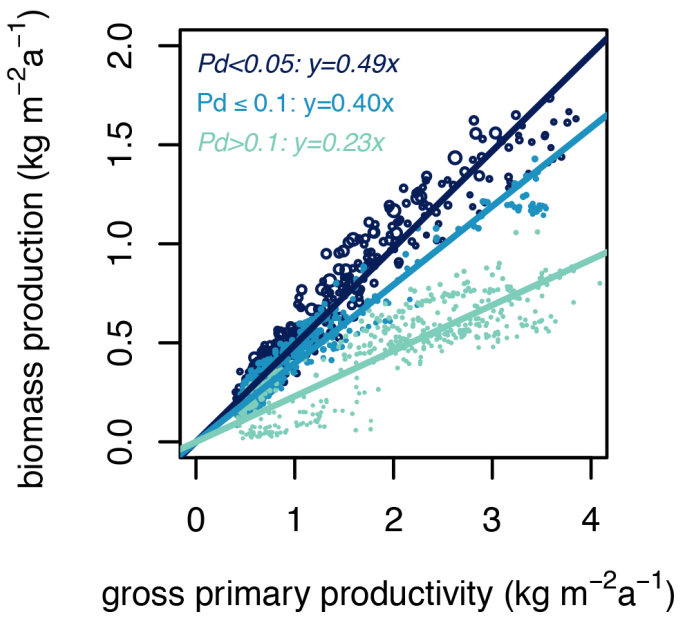

50,000 years of soil evolution

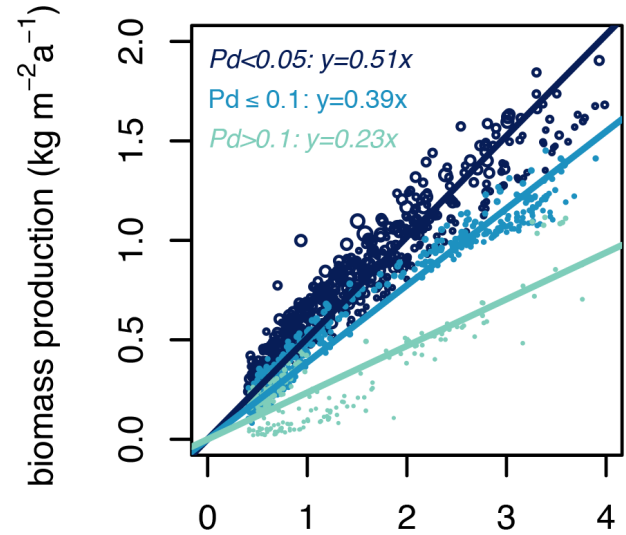

gross primary productivity $\left(\mathrm{kg} \mathrm{m}^{-2} \mathrm{a}^{-1}\right)$

data for forests from Vicca et al., 2012

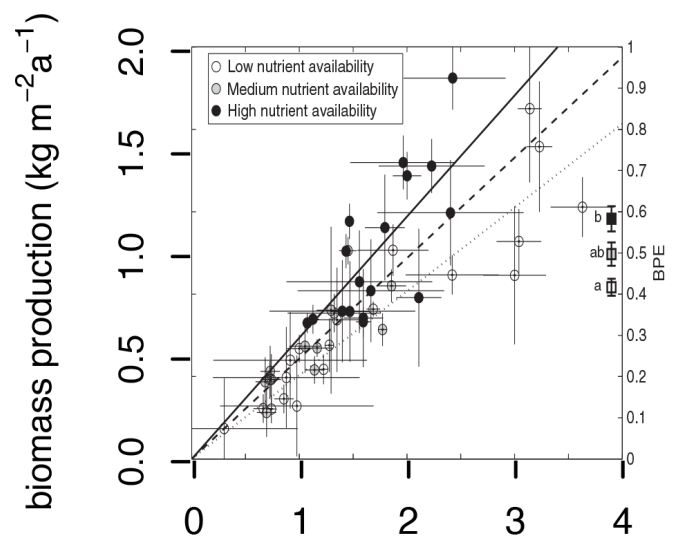

gross primary productivity $\left(\mathrm{kg} \mathrm{m}^{-2} \mathrm{a}^{-1}\right)$

Figure 13. Gross primary productivity vs. biomass production after 10000,50000 and 150000 yr of soil evolution for the BAU scenario.

as very local phenomena (Yang et al., 2013) and cannot be captured by our model (see Appendix B, Fig. B1).

\subsection{Vegetation feedbacks on $P$ availability}

We only included three feedbacks; other feedbacks that might enhance $P$ availability could also be included. We start by discussing the three feedbacks that we have included in this model, and then we discuss other possible feedbacks and how they might be implemented in the model.

About $86 \%$ of the plants have mycorrhizal associations (Lambers et al., 2008; Brundrett, 2009), about 20 to $40 \%$ of NPP is invested in root exudation (Chapin et al., 2002), and the plant allocation of carbon gained from photosynthesis to root exudates can vary from 5 to $85 \%$ (Allen et al., 2003). We found that active mycorrhizal $P$ uptake by vegetation maintains long-term terrestrial productivity. In our model the fraction of GPP invested in roots exudates increases with soil age, and can vary from 0 to $60 \%$. Biotic de-occlusion is related to root clustering, which is a morphological adaptation that allows the plant to release carbohydrates. This adaptation is common only in places with very low $\mathrm{P}$ availability (e.g. Western Australia) (Lambers et al., 2008). Our study suggests that biotic de-occlusion of $\mathrm{P}$ is not a long-term solution to $\mathrm{P}$ limitation, as the size of the occluded $\mathrm{P}$ pool is ultimately constrained by $\mathrm{P}$ inputs to the soil. Therefore, despite the high respiration cost associated with this process, in the long term the P occluded pool is depleted. Hence, biotic de-occlusion was assumed to be irrelevant for long-term dynamics and not included in the final simulations.

Root exudation induces soil respiration and therefore increases the $\mathrm{CO}_{2}$ concentration in soils, which in the short term might result in enhanced weathering rates (Berner, 1992). However, under long-term $P$ limitation, BP is reduced and hence total soil respiration. The model assumes that root 
exudates are readily respired as they reached the soil when BAU is activated as well as when it is not. In the scenarios when BAU and BD are not activated root exudation only increases soil respiration - in those scenarios the cost might be very high because the only feedback that remains is enhancement of weathering. As they are proposed in this model those feedbacks are not exclusive. In that sense including more feedback processes could reduce $\mathrm{P}$ limitation further.

In the paragraphs that follow we focus on the effect of the microbial community, independent mineralization of $\mathrm{P}$ from organic forms, and animal transfer of $\mathrm{P}$ between ecosystems.

Microbial P uptake could be an important mechanism on annual timescales with long-term consequences, preserving $\mathrm{P}$ in the ecosystem. Microbial activity is stronger during the wet period, taking up the available $\mathrm{P}$, and with this preventing it from leaching and occlusion. During the dry periods microbes die and their P becomes available for plant uptake (Resende et al., 2010). Additionally, it has been suggested that microbial $\mathrm{P}$ mineralization, which potentially also benefits plants, can be a side effect of microbial $\mathrm{C}$ acquisition (Spohn and Kuzyakov, 2013). Independent mineralization of $\mathrm{P}$, which occurs through enzymatic hydrolysis of phosphate esters, catalysed by the enzyme phosphohydrolase plays an important role in the P dynamics (Landeweert et al., 2001; McGill and Cole, 1981). In both cases, microbial dynamics could be an important mechanism for preserving $\mathrm{P}$ and making it available for plants when needed. Therefore, the inclusion of microbial contributions to $\mathrm{P}$ availability could be the next step forward.

Runyan and D'Odorico $(2012,2013)$ presented an option to model this process in cerrados. The challenge is to include these processes at the global scale without site-specific parameterization while accounting for the nitrogen cost related to it. Nitrogen fertilization studies have shown that there is an increase in phosphatase activity and with that the $\mathrm{P}$ available for vegetation (Reed et al., 2011; Kroehler and Linkins, 1988). That means that this mechanism has an associated $\mathrm{N}$ cost, which might increase the carbon cost of $\mathrm{P}$ uptake.

Animals can play an important role in nutrient cycling, as well as for redistributing nutrients between ecosystems (Vanni, 2002; Wardle et al., 2009; de Mazancourt and Schwartz, 2010; Schmitz et al., 2010). Explicitly including the effect of animals in the model is very challenging because information on animal population densities, body sizes, diet, and their movement/migration does not exist. Therefore, in a further study we suggest tackling that question from a more analytical point of view and by constraining the $\mathrm{P}$ flux from rivers/oceans to terrestrial ecosystems through a tradeoff with carbon availability.

\section{Summary and conclusions}

We described $\mathrm{P}$ dynamics during pedogenesis and its interaction with terrestrial vegetation in a simple but process-based way. Our results strongly suggest that $\mathrm{P}$ limitation of biomass production can be an important driver of terrestrial carbon cycling. We did so by coupling a model representing soil evolution accounting for the effects of climate, topography, lithology and vegetation to a model considering P dynamics. $\mathrm{P}$ constraints to biomass production result in $\mathrm{C}$ to $\mathrm{P}$ flexibility in vegetation, which provided the means to infer how much $\mathrm{C}$ is allocated to non-structural pools below ground, in order to increase $\mathrm{P}$ uptake. Although there are more possible vegetation feedbacks influencing $P$ availability, this paper considers only three of them: weathering, de-occlusion and active $\mathrm{P}$ uptake mediated by mycorrhizal associations. Only the two last processes were evaluated, as the weathering feedback could not be excluded from the simulations, and therefore could not be tested. We found that active uptake of P (BAU) is important at intermediate-to-old soil ages and across all world climate regions, except for mountain regions. De-occlusion of $\mathrm{P}$, instead, turned out to be important only at intermediate soil ages. The inclusion of $\mathrm{P}$ de-occlusion mediated by vegetation resulted in unrealistically low amounts of occluded $P$ in, especially, tropical soils, which could mean that this process is not correctly specified in the model or that this process does not alleviate $\mathrm{P}$ limitation in these old ecosystems.

The temporal and spatial dynamics of the simulations accounting for BAU are in agreement with observations from chronosequences and spatial $\mathrm{P}$ patterns. This is remarkable considering the low amount of site-specific information fed into the model.

Hence, the model presented here can be seen as proof of concept on how to consider the interaction between carbon and nutrient limitation at soil-vegetation level with that constraining vegetation productivity and thereby the global carbon cycle. Based on this approach one could include more vegetation feedback processes to evaluate whether and to what degree $\mathrm{P}$ limitation is ameliorated.

$\mathrm{P}$ constraints to biomass production and their carbonmediated feedbacks to $\mathrm{P}$ availability result in geographic variability of biomass production efficiency (BPE). We showed how BPE decreases with soil evolution and it is highly correlated with weathering. Only model simulations, which considered mycorrhiza-mediated active uptake of $\mathrm{P}$, could explain observed biomass patterns, biomass production efficiency and $\mathrm{C}: \mathrm{P}$ ratios in vegetation. This indicates how important it is to account for long-term $\mathrm{P}$ dynamics and vegetation-mediated carbon feedback mechanisms when exploring vegetation functioning and global carbon cycling with process-based models. 


\section{Appendix A: Model description}

\section{A1 Naming convention}

We followed the JESSY-SIMBA naming convention. State variables are conventionally named $A_{b}^{c}$, where $A$ is a chemical compound, e.g. P, or a state variable such as temperature $T, b$ is the state of matter, e.g. s for solid (see Table 1). Fluxes have names of the form $f A_{b t}^{s a}$, where $b$ is start and $t$ the end state (to consider phase change) and $s$ is the start and $a$ the end location. P root uptake from soil to vegetation is thus named $f \mathrm{P}_{\mathrm{d}}^{\mathrm{sv}}$. Pools start with the element, fluxes start with $f$, parameters with $p$, and constants with $c$.

\section{A2 Phosphorus balance equations}

$\frac{\mathrm{d}}{\mathrm{d} t} \mathrm{P}_{\mathrm{d}}^{\mathrm{v}}=f \mathrm{P}_{\mathrm{d}}^{\mathrm{sv}}+f \mathrm{Pyd}^{\mathrm{sv}}-f \mathrm{P}_{\mathrm{do}}^{\mathrm{v}}-f \mathrm{P}_{\mathrm{d}}^{\mathrm{vs}}$

$\frac{\mathrm{d}}{\mathrm{d} t} \mathrm{P}_{\mathrm{o}}^{\mathrm{v}}=f \mathrm{C}_{\mathrm{co}}^{\mathrm{v}}-f \mathrm{C}_{\mathrm{o}}^{\mathrm{sv}}$

$\frac{\mathrm{d}}{\mathrm{d} t} \mathrm{P}_{\mathrm{y}}^{\mathrm{s}}=f \mathrm{P}_{\mathrm{dy}}^{\mathrm{s}}-f \mathrm{Pyd}^{\mathrm{sv}}-f \mathrm{P}_{\mathrm{y}}^{\mathrm{sr}}$

$\frac{\mathrm{d}}{\mathrm{d} t} \mathrm{P}_{\mathrm{d}}^{\mathrm{s}}=f \mathrm{P}_{\mathrm{md}}^{\mathrm{s}}+f \mathrm{P}_{\mathrm{od}}^{\mathrm{s}}-f \mathrm{P}_{\mathrm{d}}^{\mathrm{sv}}-f \mathrm{P}_{\mathrm{dy}}^{\mathrm{s}}-f \mathrm{P}_{\mathrm{d}}^{\mathrm{sr}}$

$\frac{\mathrm{d}}{\mathrm{d} t} \mathrm{P}_{\mathrm{o}}^{\mathrm{s}}=f \mathrm{P}_{\mathrm{o}}^{\mathrm{vs}}-f \mathrm{C}_{\mathrm{og}}^{\mathrm{s}}$

$\frac{\mathrm{d}}{\mathrm{d} t} \mathrm{P}_{\mathrm{m}}^{\mathrm{s}}=f \mathrm{P}_{\mathrm{m}}^{\mathrm{bs}}-f \mathrm{P}_{\mathrm{md}}^{\mathrm{s}}$

\section{A3 Carbon balance equations}

$$
\begin{aligned}
\frac{\mathrm{d}}{\mathrm{d} t} \mathrm{C}_{\mathrm{c}}^{\mathrm{s}} & =f \mathrm{C}_{\mathrm{c}}^{\mathrm{vs}}-f \mathrm{C}_{\mathrm{cg}}^{\mathrm{s}}-f \mathrm{C}_{\mathrm{cy}}^{\mathrm{s}}-f \mathrm{C}_{\mathrm{c}}^{\mathrm{sr}} \\
\frac{\mathrm{d}}{\mathrm{d} t} \mathrm{C}_{\mathrm{o}}^{\mathrm{v}} & =f \mathrm{C}_{\mathrm{co}}^{\mathrm{v}}-f \mathrm{C}_{\mathrm{o}}^{\mathrm{sv}} \\
\frac{\mathrm{d}}{\mathrm{d} t} \mathrm{C}_{\mathrm{c}}^{\mathrm{v}} & =f \mathrm{C}_{\mathrm{g}}^{\mathrm{av}}-f \mathrm{C}_{\mathrm{co}}^{\mathrm{v}}-f \mathrm{C}_{\mathrm{c}}^{\mathrm{vs}}-f \mathrm{C}_{\mathrm{cg}}^{\mathrm{v}} \\
\frac{\mathrm{d}}{\mathrm{d} t} \mathrm{C}_{\mathrm{o}}^{\mathrm{s}} & =f \mathrm{C}_{\mathrm{o}}^{\mathrm{vs}}-f \mathrm{C}_{\mathrm{og}}^{\mathrm{s}} \\
\frac{\mathrm{d}}{\mathrm{d} t} \mathrm{C}_{\mathrm{y}}^{\mathrm{s}} & =f \mathrm{C}_{\mathrm{cy}}^{\mathrm{s}}-f \mathrm{C}_{\mathrm{y}}^{\mathrm{sr}}-f \mathrm{C}_{\mathrm{cy}}^{\mathrm{s}}
\end{aligned}
$$

\section{A4 Water balance equation}

$\frac{\mathrm{d}}{\mathrm{d} t} \mathrm{H}_{2} \mathrm{O}_{\mathrm{l}}{ }^{\mathrm{s}}=f \mathrm{H}_{2} \mathrm{O}_{\mathrm{l}}^{\text {as }}-f \mathrm{H}_{2} \mathrm{O}_{\mathrm{l}}^{\text {sv }}-f \mathrm{H}_{2} \mathrm{O}_{1}{ }^{\mathrm{sa}}-f \mathrm{H}_{2} \mathrm{O}_{\mathrm{l}}^{\text {sr }}-f \mathrm{H}_{2} \mathrm{O}_{\mathrm{l}}^{\text {sb }}$

The model inputs daily precipitation $\left(f \mathrm{H}_{2} \mathrm{O}_{1}{ }^{\text {as }}\right)$ and calculates, based on soil heat, vegetation coverage and vegetation water uptake $\left(f \mathrm{H}_{2} \mathrm{O}_{1}{ }^{\mathrm{sv}}\right)$, soil evapotranspiration $\left(f \mathrm{H}_{2} \mathrm{O}_{1}{ }^{\mathrm{sa}}\right)$, runoff $\left(f \mathrm{H}_{2} \mathrm{O}_{1}{ }^{\text {sr }}\right)$ and base flow $\left(f \mathrm{H}_{2} \mathrm{O}_{1}{ }^{\text {sb }}\right)$.

\section{A5 Calcium balance equations}

$$
\begin{aligned}
\frac{\mathrm{d}}{\mathrm{d} t} \mathrm{Ca}_{\mathrm{d}} & =f \mathrm{Ca}_{\mathrm{pd}}-f \mathrm{Ca}_{\mathrm{br}} \\
\frac{\mathrm{d}}{\mathrm{d} t} \mathrm{Ca}_{\mathrm{p}} & =f \mathrm{Ca}_{\mathrm{bs}}-f \mathrm{Ca}_{\mathrm{pb}}
\end{aligned}
$$


Table A1. Description of model variables relevant for the P cycle (part 1 of 3).

\begin{tabular}{|c|c|c|c|}
\hline & Symbol & Description & Units \\
\hline \multirow[t]{19}{*}{ Pools } & $\mathrm{H}_{2} \mathrm{O}_{1}{ }^{\mathrm{V}}$ & water in vegetation & $\mathrm{m}$ \\
\hline & $\mathrm{H}_{2} \mathrm{O}_{1}^{\mathrm{s}}$ & soil water & $\mathrm{m}$ \\
\hline & $\mathrm{H}_{2} \mathrm{O}_{\mathrm{s}}^{\mathrm{s}}$ & frozen soil water & $\mathrm{m}$ \\
\hline & $\mathrm{H}_{2} \mathrm{O}_{\mathrm{s}}{ }^{\text {as }}$ & snow pack & $\mathrm{m}$ \\
\hline & $\mathrm{C}_{\mathrm{O}}^{\mathrm{V}}$ & $\mathrm{C}$ in actively metabolizing vegetation biomass & $\mathrm{kgC} \mathrm{m}^{-2}$ \\
\hline & $\mathrm{C}_{\mathrm{c}}^{\mathrm{v}}$ & $\mathrm{C}$ in carbohydrates in vegetation & $\mathrm{kgC} \mathrm{m}^{-2}$ \\
\hline & $\mathrm{C}_{\mathrm{O}}^{\mathrm{s}}$ & $\mathrm{C}$ in litter and soil vegetation biomass & $\mathrm{kgC} \mathrm{m}^{-2}$ \\
\hline & $\mathrm{C}_{\mathrm{c}}^{\mathrm{s}}$ & $\mathrm{C}$ in organic acids the soil & $\mathrm{kgC} \mathrm{m}^{-2}$ \\
\hline & $\mathrm{C}_{\mathrm{y}}^{\mathrm{s}}$ & $\mathrm{C}$ in recalcitrant forms in the soil & $\mathrm{kgC} \mathrm{m}^{-2}$ \\
\hline & $\mathrm{C}_{\mathrm{g}}^{\mathrm{s}}$ & total $\mathrm{CO}_{2}$ in soil & moles $\mathrm{C} \mathrm{m}^{-2}$ \\
\hline & $\mathrm{P}_{\mathrm{m}}^{\mathrm{b}}$ & $\mathrm{P}$ in bedrock & $\mathrm{gPm}^{-2}$ \\
\hline & $\mathrm{P}_{\mathrm{m}}^{\mathrm{S}}$ & $\mathrm{P}$ in primary minerals & $\mathrm{gPm}^{-2}$ \\
\hline & $\mathrm{P}_{\mathrm{d}}^{\mathrm{s}}$ & $\mathrm{P}$ in soil solution & $\mathrm{gPm}^{-2}$ \\
\hline & $\mathrm{P}_{\mathrm{d}}^{\mathrm{v}}$ & $\mathrm{P}$ available in vegetation & $\mathrm{gPm}^{-2}$ \\
\hline & $\mathrm{P}_{\mathrm{O}}^{\mathrm{V}}$ & $\mathrm{P}$ actively metabolizing vegetation biomass & $\mathrm{gPm}^{-2}$ \\
\hline & $\mathrm{P}_{\mathrm{O}}^{\mathrm{S}}$ & $\mathrm{P}$ in soil organic matter & $\mathrm{gPm}^{-2}$ \\
\hline & $\mathrm{P}_{\mathrm{y}}^{\mathrm{s}}$ & P occluded in secondary minerals & $\mathrm{gPm}^{-2}$ \\
\hline & $\mathrm{Ca}_{\mathrm{p}}$ & $\mathrm{Ca}$ in primary minerals & $\mathrm{kgCa} \mathrm{m}^{-2}$ \\
\hline & Clay $^{\mathrm{s}}$ & Secondary minerals in the soil & $\mathrm{kg} \mathrm{m}^{-2}$ \\
\hline
\end{tabular}

Table A2. Description of model variables relevant for the P cycle (part 2 of 3).

\begin{tabular}{|c|c|c|c|}
\hline & Symbol & Description & Units \\
\hline Fluxes & $\begin{array}{l}f \mathrm{H}_{2} \mathrm{O}_{1}^{\text {as }} \\
f \mathrm{H}_{2} \mathrm{O}_{1}^{\mathrm{sv}} \\
f \mathrm{H}_{2} \mathrm{O}_{\mathrm{g}}^{\mathrm{va}} \\
f \mathrm{H}_{2} \mathrm{O}_{\mathrm{g}}^{\mathrm{sa}} \\
f \mathrm{H}_{2} \mathrm{O}_{1}^{\mathrm{ac}} \\
f \mathrm{H}_{2} \mathrm{O}_{1}^{\mathrm{sc}} \\
f \mathrm{H}_{2} \mathrm{O}_{\mathrm{sl}}^{\mathrm{as}} \\
f \mathrm{C}_{\mathrm{gc}}^{\mathrm{av}} \\
f \mathrm{C}_{\mathrm{co}}^{\mathrm{v}} \\
f \mathrm{C}_{\mathrm{cg}}^{\mathrm{V}} \\
f \mathrm{C}_{\mathrm{cg}}^{\mathrm{va}} \\
f \mathrm{C}_{\mathrm{cg}}^{\mathrm{vs}} \\
f \mathrm{C}_{\mathrm{o}}^{\mathrm{vs}} \\
f \mathrm{C}_{\mathrm{c}}^{\mathrm{vs}} \\
f \mathrm{C}_{\mathrm{cy}}^{\mathrm{s}} \\
f \mathrm{C}_{\mathrm{cg}}^{\mathrm{s}} \\
f \mathrm{C}_{\mathrm{y}}^{\mathrm{sr}} \\
f \mathrm{C}_{\mathrm{og}}^{\mathrm{ss}} \\
f \mathrm{C}_{\mathrm{d}}^{\mathrm{as}} \\
f \mathrm{C}_{\mathrm{g}}^{\mathrm{sa}}\end{array}$ & $\begin{array}{l}\text { precipitation } \\
\text { root water uptake } \\
\text { transpiration } \\
\text { evaporation } \\
\text { surface runoff } \\
\text { baseflow } \\
\text { snow melt } \\
\text { vegetation gross carbon uptake GPP } \\
\text { synthesis of actively metabolizing vegetation biomass } \\
\text { total autotrophic respiration } \\
\text { leaf respiration } \\
\text { root respiration } \\
\text { litter production } \\
\text { organic acid root exudation } \\
\mathrm{C} \text { fixation into secondary minerals } \\
\text { microbial respiration of organic acids } \\
\text { losses of recalcitrant carbon } \\
\text { soil respiration } \\
\text { input of } \mathrm{CO}_{2} \text { though rain } \\
\text { soil } \mathrm{CO}_{2} \text { efflux }\end{array}$ & $\begin{array}{l}\mathrm{m} \mathrm{s}^{-1} \\
\mathrm{~m} \mathrm{~s}^{-1} \\
\mathrm{~m} \mathrm{~s}^{-1} \\
\mathrm{~m} \mathrm{~s}^{-1} \\
\mathrm{~m} \mathrm{~s}^{-1} \\
\mathrm{~m} \mathrm{~s}^{-1} \\
\mathrm{~m} \mathrm{~s}^{-1} \\
\mathrm{~kg} \mathrm{C} \mathrm{m}^{-2} \mathrm{~s}^{-1} \\
\mathrm{~kg} \mathrm{C} \mathrm{m}^{-2} \mathrm{~s}^{-1} \\
\mathrm{~kg} \mathrm{C} \mathrm{m}^{-2} \mathrm{~s}^{-1} \\
\mathrm{~kg} \mathrm{C} \mathrm{m}^{-2} \mathrm{~s}^{-1} \\
\mathrm{~kg} \mathrm{C} \mathrm{m}^{-2} \mathrm{~s}^{-1} \\
\mathrm{~kg} \mathrm{C} \mathrm{m}^{-2} \mathrm{~s}^{-1} \\
\mathrm{~kg} \mathrm{C} \mathrm{m}^{-2} \mathrm{~s}^{-1} \\
\mathrm{~kg} \mathrm{C} \mathrm{m}^{-2} \mathrm{~s}^{-1} \\
\mathrm{~kg} \mathrm{C} \mathrm{m}^{-2} \mathrm{~s}^{-1} \\
\mathrm{~kg} \mathrm{C} \mathrm{m}^{-2} \mathrm{~s}^{-1} \\
\mathrm{kgC} \mathrm{m}^{-2} \mathrm{~s}^{-1} \\
\mathrm{moles} \mathrm{m}^{-2} \mathrm{~s}^{-1} \\
\mathrm{moles} \mathrm{m}^{-2} \mathrm{~s}^{-1}\end{array}$ \\
\hline
\end{tabular}


Table A3. Description of model variables relevant for the P cycle (part 3 of 3).

\begin{tabular}{llll}
\hline & Symbol & Description & Units \\
\hline & $f \mathrm{P}_{\mathrm{m}}^{\mathrm{bs}}$ & physical weathering & $\mathrm{g} \mathrm{P} \mathrm{m}^{-2} \mathrm{~s}^{-1}$ \\
& $f \mathrm{P}_{\mathrm{md}}^{\mathrm{s}}$ & chemical weathering & $\mathrm{g} \mathrm{P} \mathrm{m}^{-2} \mathrm{~s}^{-1}$ \\
& $f \mathrm{P}_{\mathrm{dy}}^{\mathrm{s}}$ & occlusion & $\mathrm{g} \mathrm{P} \mathrm{m}^{-2} \mathrm{~s}^{-1}$ \\
& $f \mathrm{P}_{\mathrm{O}}^{\mathrm{vs}}$ & litter production & $\mathrm{g} \mathrm{C} \mathrm{m}^{-2} \mathrm{~s}^{-1}$ \\
& $f \mathrm{P}_{\mathrm{d}}^{\mathrm{vs}}$ & $\mathrm{P}_{\mathrm{d}}$ root exudation & $\mathrm{g} \mathrm{P} \mathrm{m}^{-2} \mathrm{~s}^{-1}$ \\
& $f \mathrm{P}_{\mathrm{d}}^{\mathrm{sv}}$ & P vegetation uptake & $\mathrm{g} \mathrm{P} \mathrm{m}^{-2} \mathrm{~s}^{-1}$ \\
& $f \mathrm{P}_{\mathrm{do}}^{\mathrm{v}}$ & P synthesis to actively metabolizing vegetation biomass & $\mathrm{g} \mathrm{P} \mathrm{m}^{-2} \mathrm{~s}^{-1}$ \\
& $f \mathrm{P}_{\mathrm{od}}^{\mathrm{s}}$ & mineralization & $\mathrm{g} \mathrm{P} \mathrm{m}^{-2} \mathrm{~s}^{-1}$ \\
& $f \mathrm{P}_{\mathrm{d}}^{\mathrm{sr}}$ & losses & $\mathrm{g} \mathrm{P} \mathrm{m}^{-2} \mathrm{~s}^{-1}$ \\
& $f \mathrm{P}_{\mathrm{y}}^{\mathrm{sr}}$ & erosion of occluded P & $\mathrm{g} \mathrm{P} \mathrm{m}^{-2} \mathrm{~s}^{-1}$ \\
& $f \mathrm{P}_{\mathrm{yd}}^{\mathrm{sv}}$ & biotic de-occlusion & $\mathrm{g} \mathrm{P} \mathrm{m}^{-2} \mathrm{~s}^{-1}$ \\
& $f \mathrm{Ca} \mathrm{pd}$ & Ca chemical weathering & $\mathrm{kg} \mathrm{Ca} \mathrm{m}^{-2} \mathrm{~s}^{-1}$ \\
& $f \mathrm{Ca}$ bs & Ca physical weathering & $\mathrm{kg} \mathrm{Ca} \mathrm{m}^{-2} \mathrm{~s}^{-1}$ \\
& $f \mathrm{Clay}$ & Secondary minerals erosion & $\mathrm{kg} \mathrm{m}^{-2} \mathrm{~s}^{-1}$ \\
\hline Potential & $a f \mathrm{P}_{\mathrm{d}}^{\mathrm{sv}}$ & P active uptake function & $\mathrm{g} \mathrm{P} \mathrm{m}^{-2} \mathrm{~s}^{-1}$ \\
fluxes & $a f \mathrm{P}_{\mathrm{do}}^{\mathrm{v}}$ & P potential synthesis to actively metabolizing vegetation biomass & $\mathrm{g} \mathrm{P} \mathrm{m}^{-2} \mathrm{~s}^{-1}$ \\
& $a f \mathrm{C}_{\mathrm{co}}^{\mathrm{v}}$ & C potential synthesis to actively metabolizing vegetation biomass & $\mathrm{kg} \mathrm{C} \mathrm{m}^{-2} \mathrm{~s}^{-1}$ \\
\hline States & $\mathrm{LAI}$ & leaf area index & \\
\hline
\end{tabular}

Table A4. Description of model parameters. Parameters with the reference ${ }^{\mathrm{a}}$ are set by personal assessment (see text) while parameters marked by ${ }^{b}$ are calibrated to values, which lead to reasonable model output, considering the data used to evaluate the model.

\begin{tabular}{|c|c|c|c|c|}
\hline Parameter & Description & Value & Units & Reference \\
\hline cepot & correction of pot. evaporation & 1.30 & & \\
\hline$p \Delta Z^{\mathrm{s}}$ & soil depth & 1.0 & $\mathrm{~m}$ & $\mathrm{~b}$ \\
\hline$\epsilon$ lue & factor for light-use efficiency & 120 & & Porada et al. (2010) \\
\hline$\epsilon$ wue & factor for water-use efficiency & $3.5 \times 10^{-10}$ & & \\
\hline$p \tau \mathrm{C}_{0}^{\mathrm{V}}$ & carbon residence time in vegetation & $3.1 \times 10^{+8}$ & $\mathrm{~s}$ & Porada et al. (2010) \\
\hline$p \tau \mathrm{C}_{\mathrm{o}}^{\mathrm{s}}$ & soil carbon turnover timescale & $1.2 \times 10^{+9}$ & $\mathrm{~s}$ & Porada et al. (2010) \\
\hline$p q 10 s s$ & $Q_{10}$ value of litter decomposition & 2.0 & & Knorr and Heimann (1995) \\
\hline$p \tau \mathrm{C}_{\mathrm{c}}^{\mathrm{V}}$ & starch residence time in vegetation & $1.08 \times 10^{+08}$ & $\mathrm{~s}$ & $\mathrm{~b}$ \\
\hline$p \tau \mathrm{P}_{\mathrm{d}}^{\mathrm{v}}$ & available residence time in vegetation & $1.08 \times 10^{+09}$ & $\mathrm{~s}$ & a \\
\hline$p \tau \mathrm{P}_{\mathrm{yd}}^{\mathrm{d}}$ & $\mathrm{P}$ occlusion rate & 0.00005 & $\mathrm{~s}$ & Buendía et al. (2010) \\
\hline$p \tau a \mathrm{P}_{\mathrm{d}}^{\mathrm{sv}}$ & active uptake scaling factor & $2.5 \times 10^{+7}$ & & $\mathrm{a}$ \\
\hline$p M y \mathrm{C}_{\mathrm{cg}}$ & mycorrhizae respiration rate & 0.95 & & a \\
\hline$p B P_{\mathrm{cg}}$ & growth respiration rate & 0.25 & & a \\
\hline pmaxf $\mathrm{P}_{\mathrm{do}}$ & maximum $\mathrm{P}$ to biomass production rate & 0.8 & & a \\
\hline$p \mathrm{P}$ & concentration of $\mathrm{P}$ in primary minerals & lithology & $\mathrm{kgCm}^{-3}$ & Fig. 5 \\
\hline$p \mathrm{Ca}$ & concentration of $\mathrm{Ca}$ in primary minerals & lithology & $\mathrm{kgCm}^{-3}$ & Arens (2013) \\
\hline$c \mathrm{CP}_{\mathrm{y}}^{\mathrm{S}}$ & $\mathrm{P}$ de-occlusion exchange rate & $6 \mathrm{~mol} \mathrm{C}: 1 \mathrm{molP}$ & $\operatorname{kgC}\left(\mathrm{gP}^{-1}\right.$ & \\
\hline$c \mathrm{CP}^{\mathrm{v}}$ & actively metabolizing biomass $\mathrm{C}$ to $\mathrm{P}$ ratio & 2 & $\operatorname{kgC}\left(\mathrm{g} \mathrm{P}^{-1}\right.$ & a \\
\hline
\end{tabular}




\section{Appendix B: Comparison to other estimates}

Comparisons of modelled $\mathrm{P}$ in litter and soil organic biomass with results from Yang et al. (2013). We run the model considering biotic active $\mathrm{P}$ vegetation uptake during $70000 \mathrm{yr}$. Presenting the plots next to each other aids a better comparison.
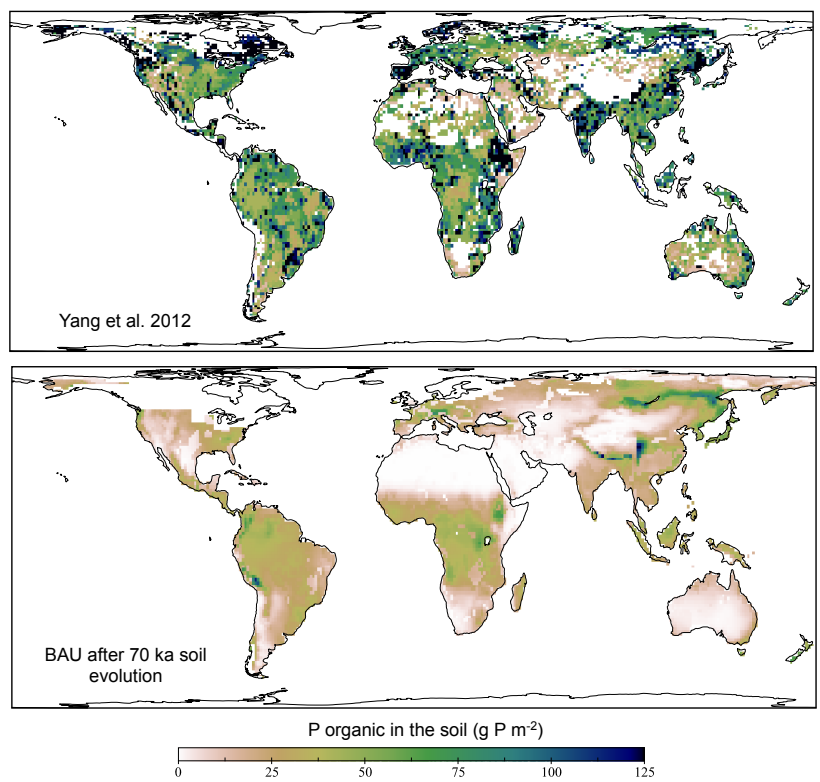

Figure B1. Global maps of $\mathrm{P}$ in the litter and soil organic matter in the soils after (upper panel) data replotted from Yang et al. (2013). Lower panel shows a modelling result after $70000 \mathrm{yr}$ soil evolution, taking into account the active $\mathrm{P}$ uptake mediated by root exudation.
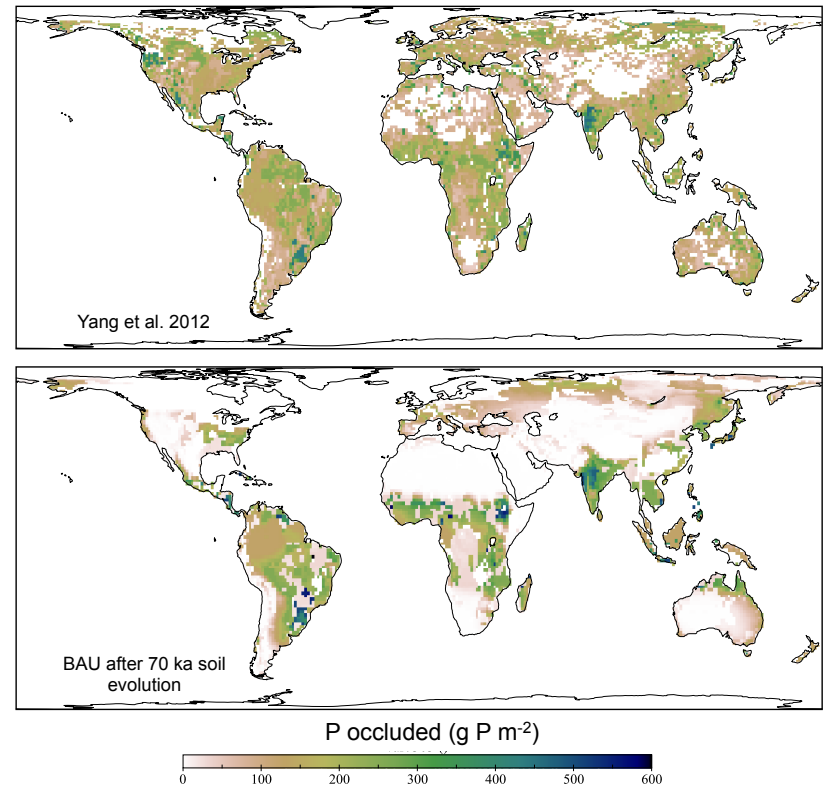

Figure B2. Global maps of $\mathrm{P}$ in occluded forms (upper plot) replotted from Yang et al. (2013). Lower map: model results after $70000 \mathrm{yr}$ of soil evolution, taking into account the active $\mathrm{P}$ uptake. 
Acknowledgements. We would like to thank especially Steffen Richter for helping us in different aspects of programming and debugging the code of the model, and for writing the user manual of the model. We thank Ryan Pavlick, Björn Reu, Stan Schymanski, Carlos Sierra, and Sönke Zähle for their feedback on model structure. We thank Christiane Runyan and an anonymous reviewer for comments that greatly improved the paper. We thank Kerry Hinds, Jens Kattge and Myroslava Khomik for comments and corrections of the paper. We also thank Xiaojuan Yang for providing data for model results comparison. TH acknowledges support from the research funding programme LOEWE-Landesoffensive zur Entwicklung Wissenschaftlich-ökonomischer Exzellenz of Hesse's Ministry of Higher Education.

The service charges for this open access publication have been covered by the Max Planck Society.

Edited by: C. P. Slomp

\section{References}

Allen, M., Swenson, W., Querejeta, J., Egerton-Warburton, L., and Treseder, K.: Ecology of mycorrhizae: a conceptual framework for complex interactions among plants and fungi, Annu. Rev. Phytopathol., 41, 271-303, 2003.

Amiotte Suchet, P. and Probst, J.-L.: A global 1 degree by 1 degree distribution of atmospheric/soil $\mathrm{CO}_{2}$ consumption by continental weathering and of riverine $\mathrm{HCO}_{3}$ yield, Technical report, Centre National de la Recherche Scientifique, Center de Geochemie de la Surface, 1995.

Arens, S.: Global limits on silicate weathering and implications for the silicate weathering feedback, 2013.

Arens, S. and Kleidon, A.: Eco-hydrological versus supply-limited weathering regimes and the potential for biotic enhancement of weathering at the global scale, Appl. Geochem., 26, 274-278, 2011

Bais, H. P., Weir, T. L., Perry, L. G., Gilroy, S., and Vivanco, J. M.: The role of root exudates in rhizosphere interactions with plants and other organisms, Annu. Rev. Plant Biol., 57, 233-266, 2006.

Banfield, J. F., Barker, W. W., Welch, S. A., and Taunton, A.: Biological impact on mineral dissolution: application of the lichen model to understanding mineral weathering in the rhizosphere, $\mathrm{P}$. Natl. Acad. Sci., 96, 3404-3411, 1999.

Beer, C., Reichstein, M., Tomelleri, E., Ciais, P., Jung, M., Carvalhais, N., Rodenbeck, C., Arain, M. A., Baldocchi, D., Bonan, G. B., Bondeau, A., Cescatti, A., Lasslop, G., Lindroth, A., Lomas, M., Luyssaert, S., Margolis, H., Oleson, K. W., Roupsard, O., Veenendaal, E., Viovy, N., Williams, C., Woodward, F. I., and Papale, D.: Terrestrial Gross Carbon Dioxide Uptake: Global Distribution and Covariation with Climate, Science, 329, 834838,2010

Berner, R. A.: Weathering, plants, and the long-term carbon cycle, Geochim. Cosmochim. Ac., 56, 3225-3231, 1992.

Brady, N. C. and Weil, R. R.: The Nature and Properties of Soil, Prentice Hall, 13 edn., 2008.

Brundrett, M. C.: Mycorrhizal associations and other means of nutrition of vascular plants: understanding the global diversity of host plants by resolving conflicting information and developing reliable means of diagnosis, Plant Soil, 320, 37-77, 2009.
Buendía, C., Kleidon, A., and Porporato, A.: The role of tectonic uplift, climate and vegetation in the long-term terrestrial phosphorus cycle, Biogeosciences, 7, 2025-2038, doi:10.5194/bg-72025-2010, 2010.

Canadell, J. G., Pataki, D. E., Gifford, R., Houghton, R. A., Luo, Y., Raupach, M. R., Smith, P., and Steffen, W.: Saturation of the terrestrial carbon sink, in: Terrestrial ecosystems in a changing world, 59-78, Springer, 2007.

Cernusak, L. A., Winter, K., Dalling, J. W., Holtum, J. A. M., Jaramillo, C., Körner, C., Leakey, A. D. B., Norby, R. J., Poulter, B., Turner, B. L., and Wright, S. J.: Tropical forest responses to increasing atmospheric $\mathrm{CO}_{2}$ : current knowledge and opportunities for future research, Funct. Plant Biol., 40, 531-551, doi:10.1071/FP12309, 2013.

Chapin, S., Matson, A., and Mooney, A.: Terrestrial production processes, Principles of terrestrial ecosystem ecology, 123-150, 2002.

Cramer, W., Kicklighter, D., Bondeau, A., Iii, B. M., Churkina, G., Nemry, B., Ruimy, A., Schloss, A., and ThE Intercomparison, and Participants OF ThE Potsdam NpP Model: Comparing global models of terrestrial net primary productivity (NPP): overview and key results, Glob. Change Biol., 5, 1-15, 1999.

Crews, T., Kitayama, K., Fownes, J., and Riley, R.: Changes in soil phosphorus fractions and ecosystem dynamics across a long chronosequence in Hawaii, Ecology, 75, 1407-1424, 1995.

Cuevas, E. and Medina, E.: Nutrient dynamics within Amazonian forests. II. Fine root growth, nutrient availability and leaf litter decomposition, Oecologia, 76, 222-235, 1988.

Davidson, E. A. and Janssens, I. A.: Temperature sensitivity of soil carbon decomposition and feedbacks to climate change, Nature, 440, 165-173, 2006.

de Mazancourt, C. and Schwartz, M. W.: A resource ratio theory of cooperation, Ecol. Lett., 13, 349-359, 2010.

DeLonge, M., Vandecar, K. L., D’Odorico, P., and Lawrence, D.: The impact of changing moisture conditions on short-term $\mathrm{P}$ availability in weathered soils, Plant Soil, 365, 201-209, 2013.

DeLucia, E., Callaway, R., Thomas, E., and Schlesinger, W.: Mechanisms of phosphorus acquisition for ponderosa pine seedlings under high $\mathrm{CO}_{2}$ and temperature, Ann. Bot., 79, 111-120, 1997.

Filippelli, G. M.: The global phosphorus cycle, Rev. Mineral. Geochem., 48, 391-425, 2002.

Filippelli, G. M.: The Global Phosphorus Cycle: Past, Present, and Future, Elements, 4, 89-95, 2008.

Gardner, L.: The role of rock weathering in the phosphorus budget of terrestrial watersheds, Biogeochemistry, 11, 97-110, 1990.

Gholz, H. L., Wedin, D. A., Smitherman, S. M., Harmon, M. E., and Parton, W. J.: Long-term dynamics of pine and hardwood litter in contrasting environments: toward a global model of decomposition, Glob. Change Biol., 6, 751-765, 2000.

Goll, D. S., Brovkin, V., Parida, B. R., Reick, C. H., Kattge, J., Reich, P. B., van Bodegom, P. M., and Niinemets, Ü.: Nutrient limitation reduces land carbon uptake in simulations with a model of combined carbon, nitrogen and phosphorus cycling, Biogeosciences, 9, 3547-3569, doi:10.5194/bg-9-3547-2012, 2012.

Hilley, G. E. and Porder, S.: A framework for predicting global silicate weathering and $\mathrm{CO}_{2}$ drawdown rates over geologic timescales, Proceedings of the National Academy of Sciences, 105, 16855-16859, 2008 
IGBP-DIS, S.: A program for creating global soil-property databases, IGBP Global Soils Data Task, France, 1998.

Jakobsen, I. and Rosendahl, L.: Carbon flow into soil and external hyphae from roots of mycorrhizal cucumber plants, New Phytol., 115, 77-83, 1990.

Jenny, H.: Role of the plant factor in the pedogenic functions, Ecology, 39, 5-16, 1958.

Jordan, C. F.: The nutrient balance of an amazonian rain forest, Ecology, 61, 14-18, 1982.

Junk, W. J., Piedade, M. T. F., Schöngart, J., Cohn-Haft, M., Adeney, J. M., and Wittmann, F.: A Classification of Major Naturally-Occurring Amazonian Lowland Wetlands, Wetlands, 31, 623-640, 2011.

Knorr, W. and Heimann, M.: Impact of drought stress and other factors on seasonal land biosphere $\mathrm{CO}_{2}$ exchange studied through an atmospheric tracer transport model, Tellus B, 47, 471-489, 1995.

Körner, C.: Plant $\mathrm{CO}_{2}$ responses: an issue of definition, time and resource supply, New Phytol., 172, 393-411, 2006.

Kroehler, C. J. and Linkins, A. E.: The root surface phosphatases of Eriophorum vaginatum: Effects of temperature, $\mathrm{pH}$, substrate concentration and inorganic phosphorus, Plant Soil, 105, 3-10, 1988.

Kunc, F. and Macura, J.: Decomposition of root exudates in soil, Folia Microbiol., 11, 239-247, 1966.

Lambers, H., Raven, J. A., Shaver, G. R., and Smith, S. E.: Plant nutrient-acquisition strategies change with soil age, Trends Ecol. Evol., 23, 95-103, 2008.

Landeweert, R., Hoffland, E., Finlay, R. D., Kuyper, T. W., and van Breemen, N.: Linking plants to rocks: ectomycorrhizal fungi mobilize nutrients from minerals, Trends Ecol. Evol., 16, 248-254, 2001.

Lavigne, M. B. and Ryan, M. G.: Growth and maintenance respiration rates of aspen, black spruce and jack pine stems at northern and southern BOREAS sites, Tree Physiol., 17, 543-551, 1997.

Lenton, T. M.: The role of land plants, phosphorus weathering and fire in the rise and regulation of atmospheric oxygen, Glob. Change Biol., 7, 613-629, 2001.

Mahowald, N. M., Artaxo, P., Baker, A. R., Jickells, T. D., Okin, G. S., Randerson, J. T., and Townsend, A. R.: Impacts of biomass burning emissions and land use change on Amazonian atmospheric phosphorus cycling and deposition, Global Biogeochem. Cy., 19, GB4030, doi:10.1029/2005GB002541, 2005.

McGill, W. and Cole, C.: Comparative aspects of cycling of organic C, N, S and P through soil organic matter, Geoderma, 26, 267286, doi:10.1016/0016-7061(81)90024-0, 1981.

Menge, D. N., Hedin, L. O., and Pacala, S. W.: Nitrogen and Phosphorus Limitation over Long-Term Ecosystem Development in Terrestrial Ecosystems, PloS One, 7, e42045, doi:10.1371/journal.pone.0042045, 2012.

Mercado, L. M., Patiño, S., Domingues, T. F., Fyllas, N. M., Weedon, G. P., Sitch, S., Quesada, C. A., Phillips, O. L., Aragão, L. E., Malhi, Y., Dolman, J., Restrepo-Coupe, N., Saleska, S. R., Baker, T. R., Almeida, S., Higuchi, N., and Lloyd, J.: Variations in Amazon forest productivity correlated with foliar nutrients and modelled rates of photosynthetic carbon supply, Philos. T. R. Soc. B, 366, 3316-3329, 2011.

Newman, E.: Phosphorus inputs to terrestrial ecosystems, J. Ecol., 83, 713-726, 1995.
Pauliquevis, T., Lara, L. L., Antunes, M. L., and Artaxo, P.: Aerosol and precipitation chemistry measurements in a remote site in Central Amazonia: the role of biogenic contribution, Atmos. Chem. Phys., 12, 4987-5015, doi:10.5194/acp-12-4987-2012, 2012.

Porada, P., Arens, S., Buendía, C., Gans, F., Schymanski, S., and Kleidon, A.: A simple global land surface model for biogeochemical studies, Tech. Rep. 18, Max-Planck-Institute for Biogeochemistry, 2010.

Porada, P., Weber, B., Elbert, W., Pöschl, U., and Kleidon, A.: Estimating global carbon uptake by lichens and bryophytes with a process-based model, Biogeosciences, 10, 6989-7033, doi:10.5194/bg-10-6989-2013, 2013.

Quesada, C. A., Phillips, O. L., Schwarz, M., Czimczik, C. I., Baker, T. R., Patiño, S., Fyllas, N. M., Hodnett, M. G., Herrera, R., Almeida, S., Alvarez Dávila, E., Arneth, A., Arroyo, L., Chao, K. J., Dezzeo, N., Erwin, T., di Fiore, A., Higuchi, N., Honorio Coronado, E., Jimenez, E. M., Killeen, T., Lezama, A. T., Lloyd, G., López-González, G., Luizão, F. J., Malhi, Y., Monteagudo, A., Neill, D. A., Núñez Vargas, P., Paiva, R., Peacock, J., Peñuela, M. C., Peña Cruz, A., Pitman, N., Priante Filho, N., Prieto, A., Ramírez, H., Rudas, A., Salomão, R., Santos, A. J. B., Schmerler, J., Silva, N., Silveira, M., Vásquez, R., Vieira, I., Terborgh, J., and Lloyd, J.: Basin-wide variations in Amazon forest structure and function are mediated by both soils and climate, Biogeosciences, 9, 2203-2246, doi:10.5194/bg-9-2203-2012, 2012.

Reed, S. C., Townsend, A. R., Taylor, P. G., and Cleveland, C. C.: Phosphorus cycling in tropical forests growing on highly weathered soils, in: Phosphorus in Action, 339-369, Springer, 2011.

Resende, J. C. F., Markewitz, D., Klink, C. A., Bustamante, M. M. d. C., and Davidson, E. A.: Phosphorus cycling in a small watershed in the Brazilian Cerrado: impacts of frequent burning, Biogeochemistry, 105, 105-118, 2010.

Runyan, C. W. and D'Odorico, P.: Hydrologic controls on phosphorus dynamics: A modeling framework, Adv. Water Resour., 35, 94-109, 2012.

Runyan, C. W. and D'Odorico, P.: Positive feedbacks and bistability associated with phosphorus-vegetation-microbial interactions, Adv. Water Resour., 52, 151-164, 2013.

Saatchi, S. S., Harris, N. L., Brown, S., Lefsky, M., Mitchard, E. T., Salas, W., Zutta, B. R., Buermann, W., Lewis, S. L., Hagen, S., Petrova, C., White, L., Silman, M., and Morel, A.: Benchmark map of forest carbon stocks in tropical regions across three continents, P. Natl. Acad. Sci., 108, 9899-9904, 2011.

Sardans, J. and Peñuelas, J.: The role of plants in the effects of global change on nutrient availability and stoichiometry in the plant-soil system, Plant Physiol., 160, 1741-1761, 2012.

Scheffer, M., Carpenter, S., Foley, J. A., Folke, C., and Walker, B.: Catastrophic shifts in ecosystems, Nature, 413, 591-596, 2001.

Schlesinger, W.: Biogeochemistry: An analysis of Global change, Academic Press, 2nd edn., 1997.

Schmitz, O. J., Hawlena, D., and Trussell, G. C.: Predator control of ecosystem nutrient dynamics, Ecol. Lett., 13, 1199-1209, doi:10.1111/j.1461-0248.2010.01511.x, 2010.

Sheffield, J., Goteti, G., and Wood, E. F.: Development of a 50-year high-resolution global dataset of meteorological forcings for land surface modeling, J. Climate, 19, 3088-3111, 2006. 
Spohn, M. and Kuzyakov, Y.: Phosphorus mineralization can be driven by microbial need for carbon, Soil Biol. Biochem., 61, 69-75, 2013.

Taylor, L., Leake, J., Quirk, J., Hardy, K., Banwart, S., and Beerling, D.: Biological weathering and the long-term carbon cycle: integrating mycorrhizal evolution and function into the current paradigm, Geobiology, 7, 171-191, 2009.

Vanni, M. J.: Nutrient cycling by animals in freshwater ecosystems, Annu. Rev. Ecol. Syst., 33, 341-370, 2002.

Vicca, S., Luyssaert, S., Peñuelas, J., Campioli, M., Chapin III, F. S., Ciais, P., Heinemeyer, A., Högberg, P., Kutsch, W. L., Law, B. E., Malhi, Y., Papale, D., Piao, S. L., Reichstein, M., Schulze, E. D., and Janssens, I. A.: Fertile forests produce biomass more efficiently, Ecol. Lett., 15, 520-526, 2012.

Vitousek, P. M. and Sanford, R. L., J.: Nutrient Cycling in Moist Tropical Forest, Annu. Rev. Ecol. Syst., 17, 137-167, 1986.

Walker, T. W. and Syers, J. K.: The fate of phosphorous during pedogenesis, Geoderma, 15, 1-19, 1976.

Wang, Y. P., Houlton, B., and Field, C. B.: A model of biogeochemical cycles of carbon, nitrogen and phosphorus including symbiotic nitrogen fixation and phosphatase production, Global Biogeochem. Cy., 21, GB1018, doi:10.1029/2006GB002797, 2007.

Wang, Y. P., Law, R. M., and Pak, B.: A global model of carbon, nitrogen and phosphorus cycles for the terrestrial biosphere, Biogeosciences, 7, 2261-2282, doi:10.5194/bg-7-2261-2010, 2010.
Wardle, D. A., Walker, L. R., and Bardgett, R. D.: Ecosystem properties and forest decline in contrasting long-term chronosequences, Science, 305, 509-513, 2004.

Wardle, D. A., Bellingham, P. J., Bonner, K. I., and Mulder, C. P. H.: Indirect effects of invasive predators on litter decomposition and nutrient resorption on seabird-dominated islands, Ecology, 90, 452-464, 2009.

Wittmann, F., Schöngart, J., Montero, J. C., Motzer, T., Junk, W. J., Piedade, M. T. F., Queiroz, H. L., and Worbes, M.: Tree species composition and diversity gradients in white-water forests across the Amazon Basin, J. Biogeogr., 33, 1334-1347, 2006.

Yang, X., Post, W. M., Thornton, P. E., and Jain, A.: The distribution of soil phosphorus for global biogeochemical modeling, Biogeosciences, 10, 2525-2537, doi:10.5194/bg-10-2525-2013, 2013.

Yang, X., Thornton, P. E., Ricciuto, D. M., and Post, W. M.: The role of phosphorus dynamics in tropical forests - a modeling study using CLM-CNP, Biogeosciences, 11, 1667-1681, doi:10.5194/bg-11-1667-2014, 2014.

Zhang, Q., Wang, Y., Pitman, A., and Dai, Y.: Limitations of nitrogen and phosphorous on the terrestrial carbon uptake in the 20th century, Geophys. Res. Lett., 38, L22701, doi:10.1029/2011GL049244, 2011. 